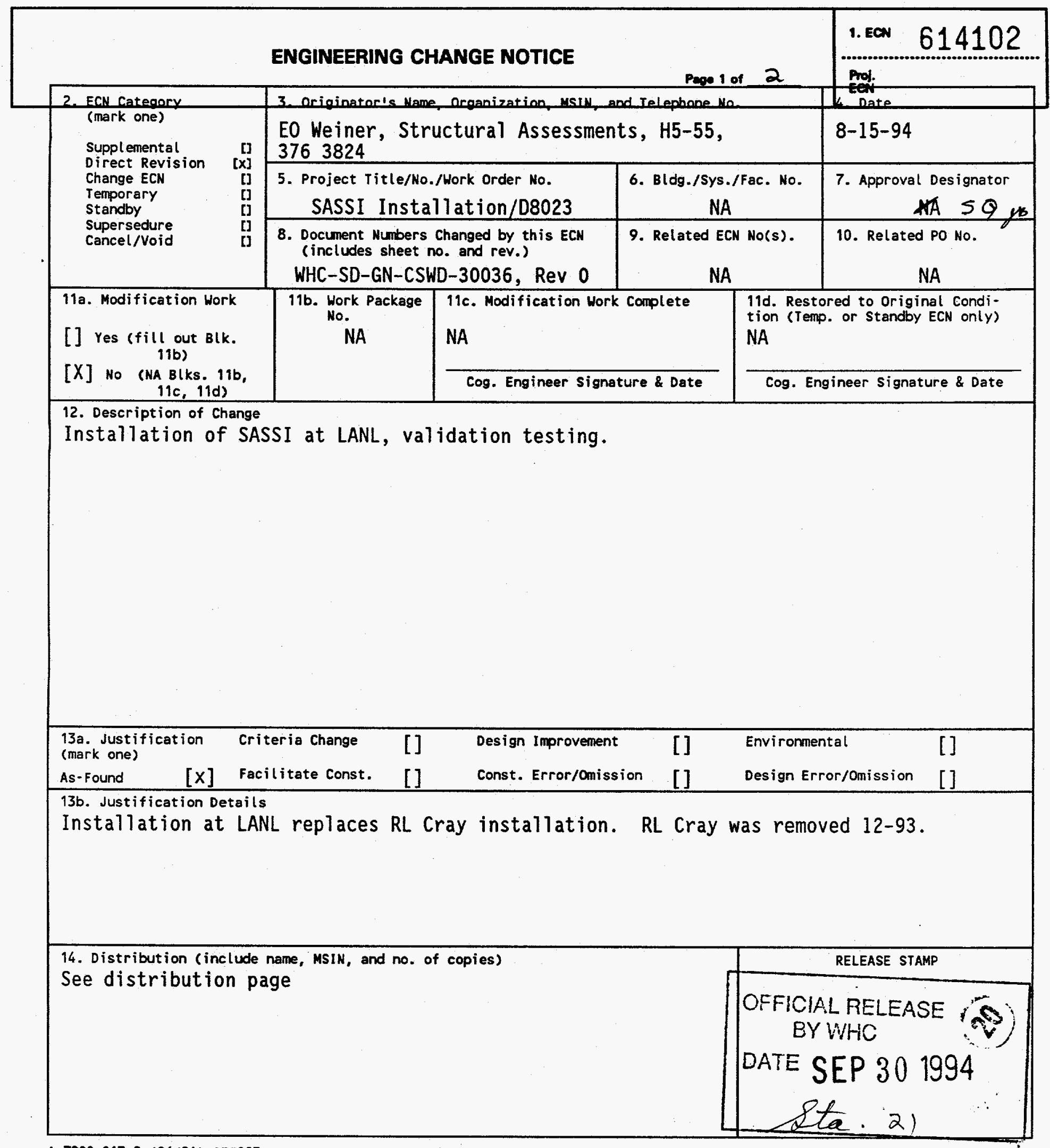

A-7900-013-2 (06/94) GEF095 


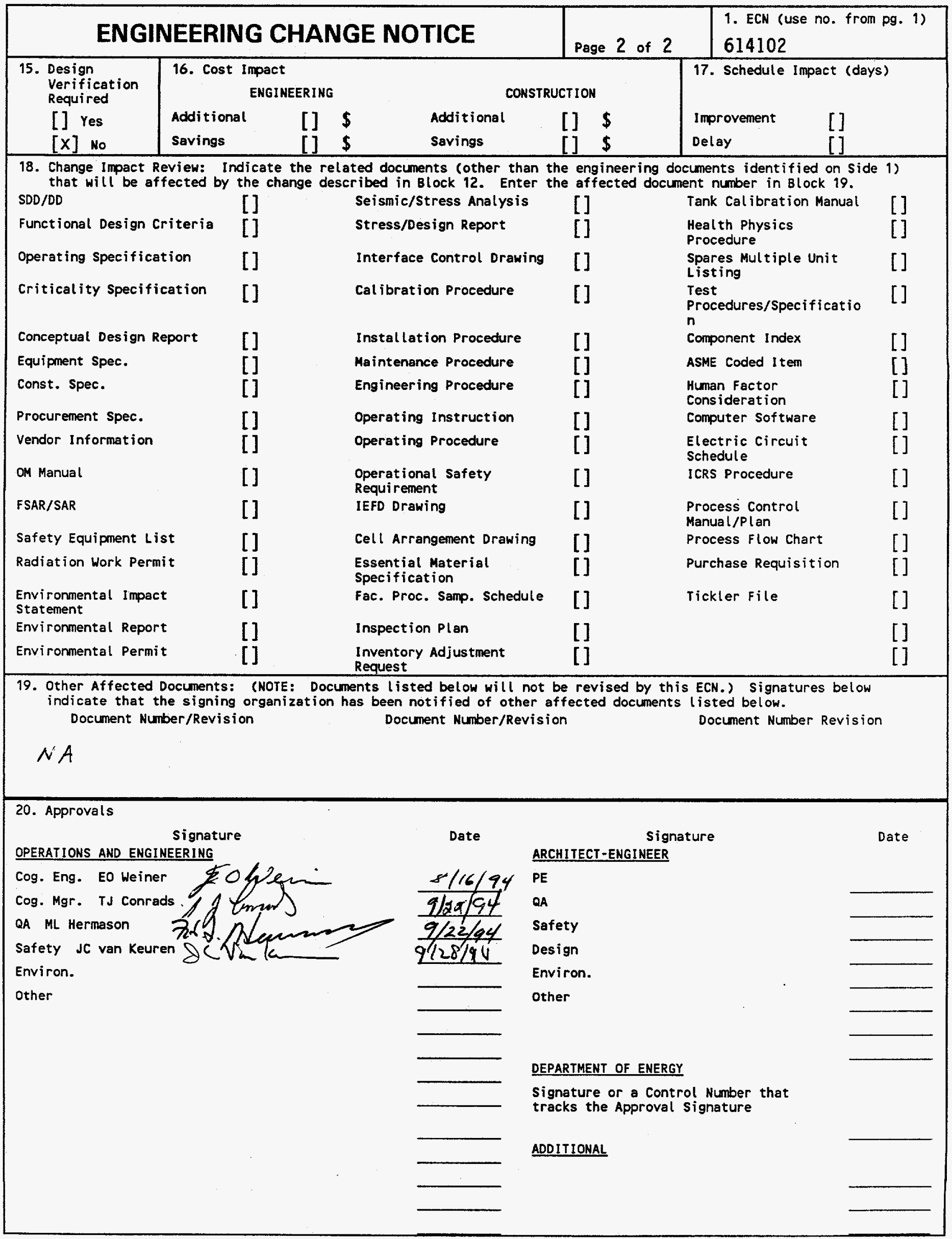




\section{DISCLAIMER}

Portions of this document may be illegible in electronic image products. Images are produced from the best available original document. 


\section{RELEASE AUTHORIZATION}

Document Number: $\quad$ WHC-SD-GN-CSWD-30036, REV. 1

Document Title: SASSI System Software Configuration

Release Date: $\quad 9 / 30 / 94$

This document was reviewed following the procedures described in WHC-CM-3-4 and is:

APPROVED FOR PUBLIC RELEASE

**************

WHC Information Release Administration Specialist:

4.g.oulis N.L. SOLIS

(Signature)

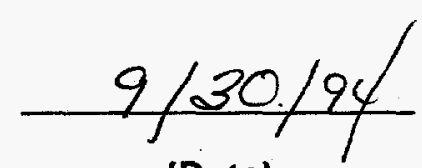

(Date) 


\begin{tabular}{|c|c|}
\hline $\begin{array}{l}\text { 2. Title } \\
\text { SASSI System Software Configuration }\end{array}$ & $\begin{array}{l}\text { 3. Number } \\
\text { WHC-SD-GN-CSWD- } \\
30036\end{array}$ \\
\hline $\begin{array}{l}\text { 5. Key words } \\
\text { software, configuration, SASSI, seismic }\end{array}$ & $\begin{array}{l}\text { 6. Author } \\
\text { Name:E0 Weiner } \\
\text { Organization/Charge code 8D440/08023 }\end{array}$ \\
\hline $\begin{array}{l}\text { 7. Abstract } 9 / 30 / 94 \mathrm{O} \text { dolil } \\
\text { This document demonstrates compliance of the SASSI s } \\
\text { computer program with WHC-CM-3-10 }\end{array}$ & e interact \\
\hline 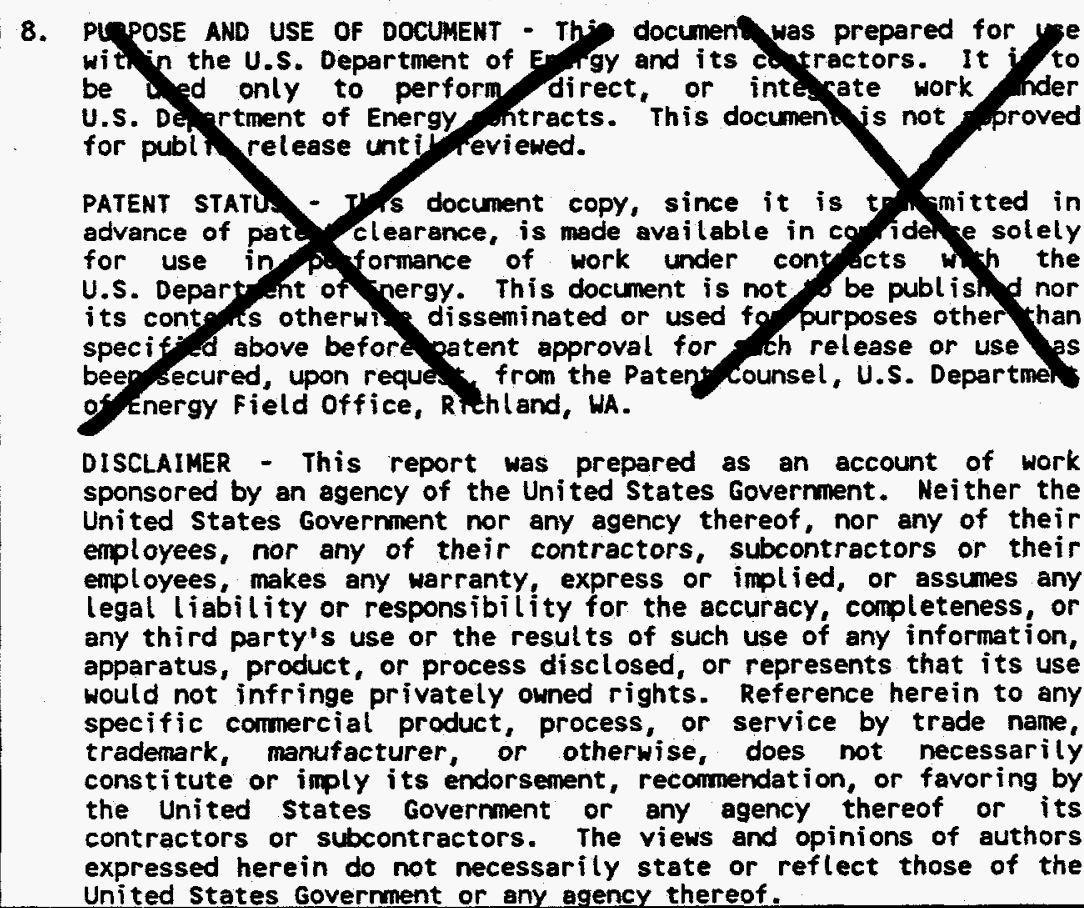 & $\begin{array}{l}\text { OFFICIAL RELEASE } 20 \\
\text { BYWHIC } \\
\text { DATE SEP } 30.1994 \\
\text { \&A. } 21\end{array}$ \\
\hline
\end{tabular}


RECORD OF REVISION

(2) Title

SASSI System Software Configuration

CHANGE CONTROL RECORD

(3) Revision Q

1 RS
(1) Document Number

WHC-SD-GN-CSWD30036

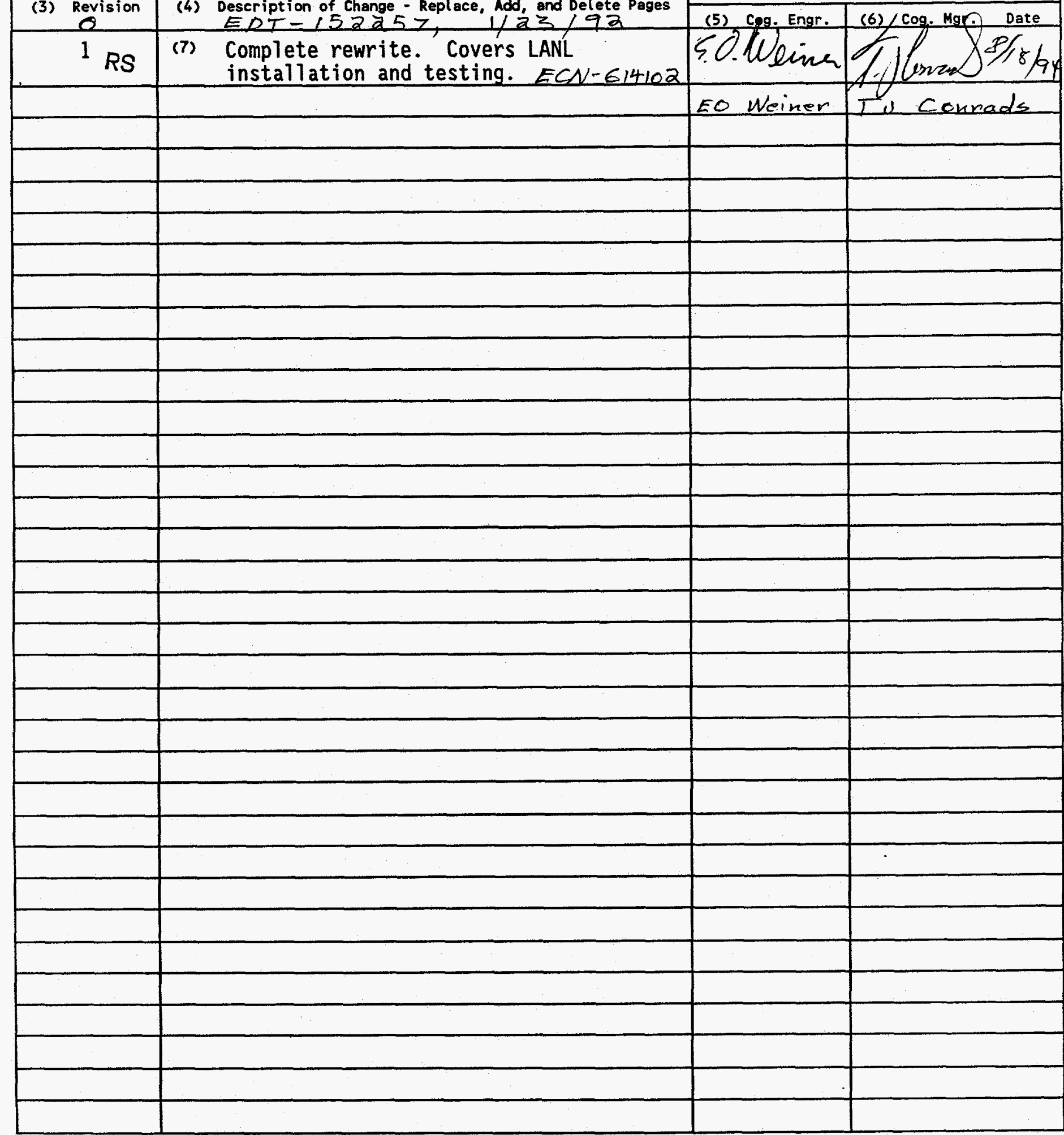


SASSI System Software Configuration

August 1994

Prepared by: $\$ 0$ Ue

EO Weiner

Structural Assessments

Reviewed by:
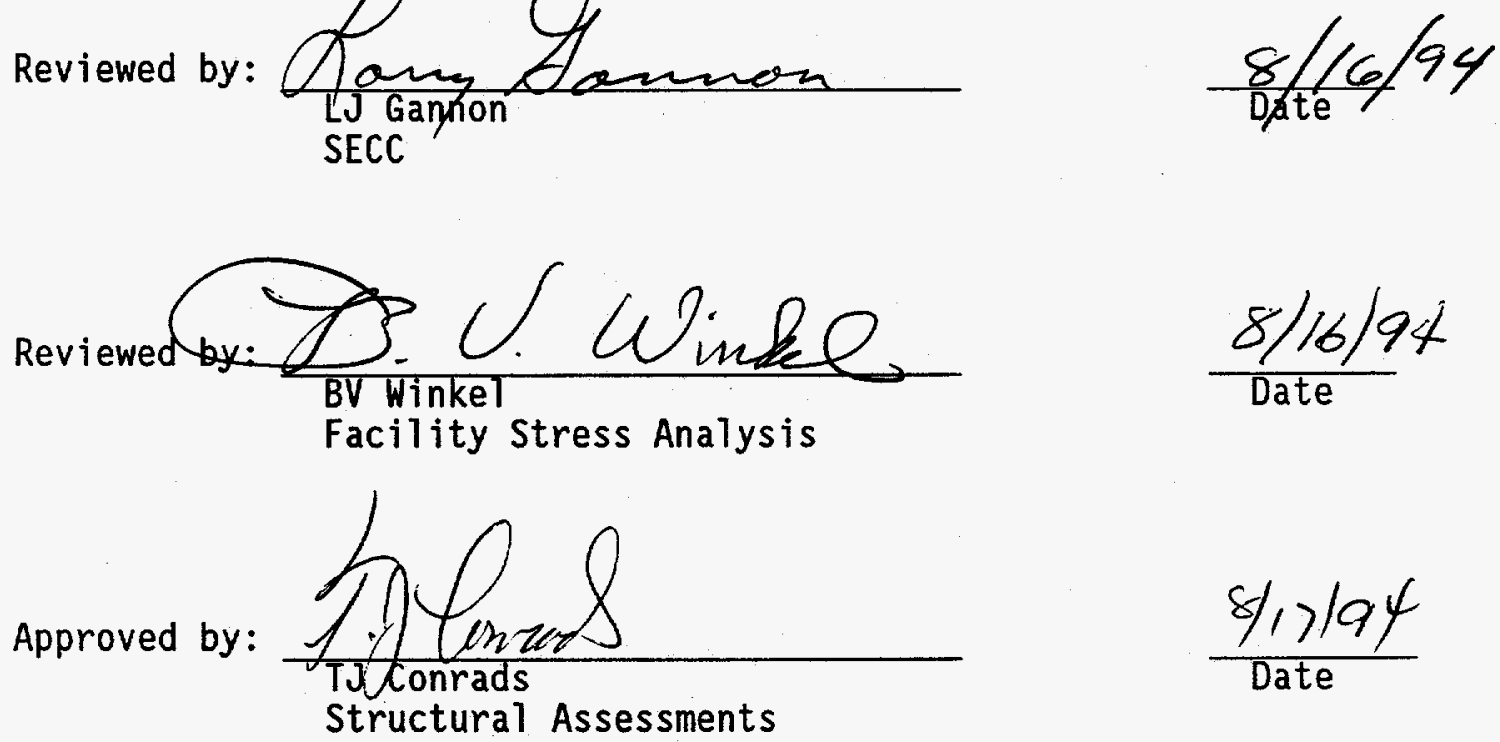

$\frac{8 / 7 / 94}{\text { Date }}$

Westinghouse Hanford Company

Hanford Operations and Engineering Contractor for the Department of Energy 
TABLE OF CONTENTS

\author{
INTRODUCTION \\ IMPACT LEVEL \\ DOCUMENTATION \\ SOFTWARE DEVELOPMENT PLAN \\ VERIFICATION \\ VALIDATION \\ CONVERSION \\ CONFIGURATION MANAGEMENT \\ REVISIONS \\ REFERENCES
}




$$
\begin{gathered}
W H C-S D-G N-C S W D-30036 \\
\operatorname{ReV} 1
\end{gathered}
$$

ii

TYPICAL CHECKLIST FOR INDEPENDENT REVIEW

Document Reviewed SASSI System Software Configuration Author E.O. Werner

Yes No N/A

$\left[\begin{array}{llllll} & 1 & 1 & 1 & 1 & 1\end{array}\right.$

[ $\sqrt{ }]\left[\begin{array}{lllllll} & 1 & 1 & 1 & 1\end{array}\right.$ Necessary assumptions explicitly stated and supported.

[M $[$ ] [ ] Computer codes and data files documented.

[V] [ ] [ ] Data used in calculations explicitly stated in document.

[C] l ] 1 "Data checked for consistency with original source information as applicable.

[ l [ ] IV] Mathematical derivations checked including dimensional consistency of results.

[ I [ ] [M Models appropriate and used within range of validity or use outside range of established validity justified.

[ ] I I [ I H Hand calculations checked for errors.

[ $]$ i $][$ ] Code run streams correct and consistent with analysis documentation.

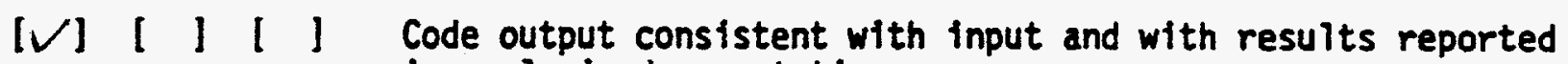
in analysis documentation.

[ $][$ l $[$ ] Acceptability 1 limits on analytical results applicable and supported. Limits checked against sources.

l ] I ] [ T Safety margins consistent with good engineering practices.

[V $]$ l $]$ [ ] Conclusions consistent with analytical results and. applicable limits.

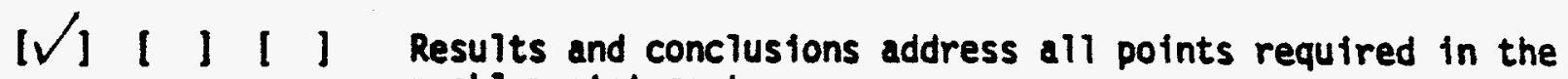
problem statement.

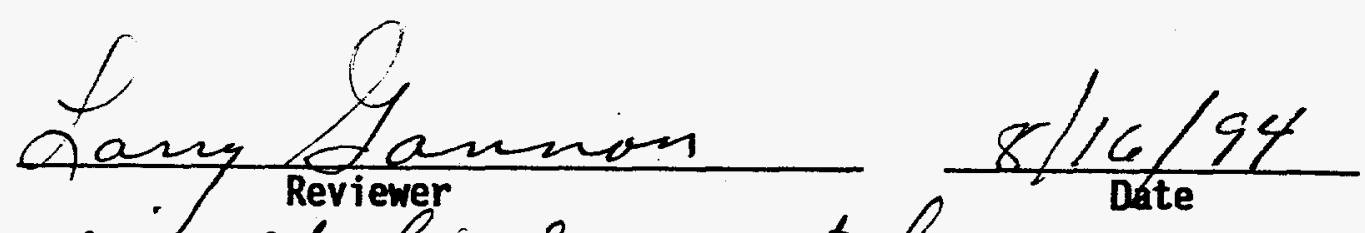

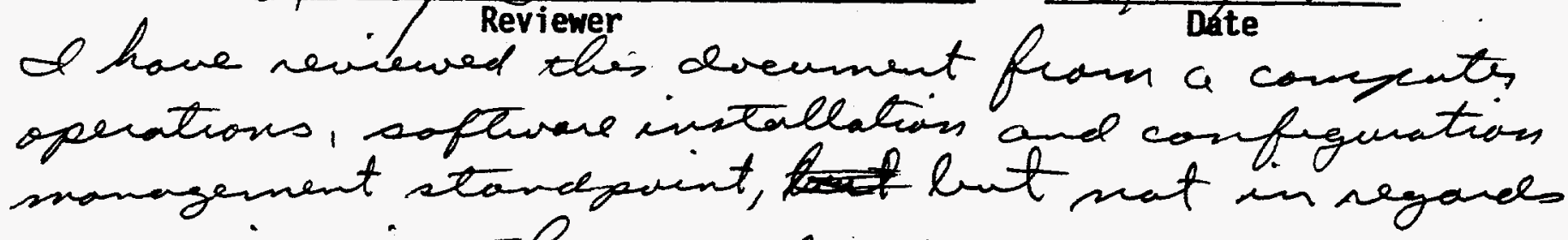
to engineering theory and usage. 
Document Reviewed SASSI System Soffware Confeguration Author E.O. Weiner

Yes No N/A

I $\[$ ] $]$ Problem completely defined.

[ $\sqrt{ }] \quad[\quad l l l l$ Necessary assumptions explicitly stated and supported.

$[1$ l 1 [ ] computer codes and data files documented.

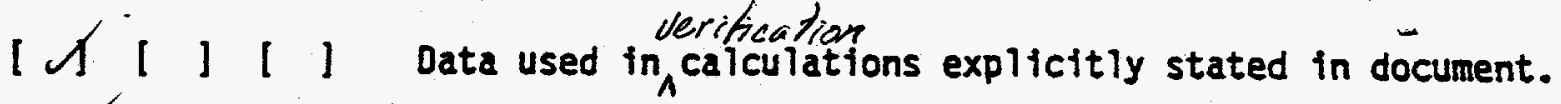

$\left[\begin{array}{lllll} & 1 & 1 & 1\end{array}\right]$ Data checked for consistency with original source information as applicable.

[ 1$]\left[\begin{array}{lll}1 & {[} & 1\end{array}\right]$ Mathematical derivations checked including dimensional consistency of results.

$[\mathcal{I}[1[1]$ Models, appropriate and used within range of valfdity or use outside range of established validity justified.

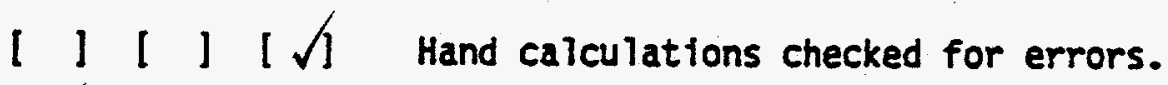
$[/]\left[1[1] \begin{array}{l}\text { Code run streams correct and consistent with analysis } \\ \text { documentation. }\end{array}\right.$

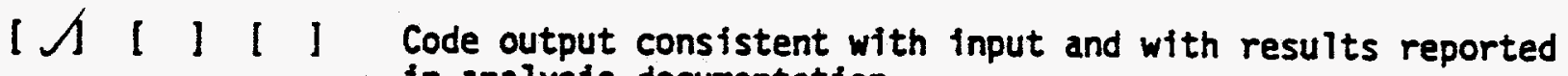
in analysis documentation.

$$
\text { (Ueritication problem) }
$$

[ $\backslash[1]$ [ Acceptability limits on analytical, results applicable and supported. Limits checked against sources.

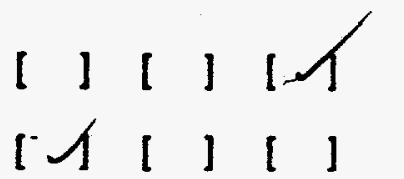

$[1,1] 1$

Safety margins consistent with good engineering practices.

Conclusions consistent with analytical resuits and applicable limits.

Results and conclusions address all points required in the problem statement.

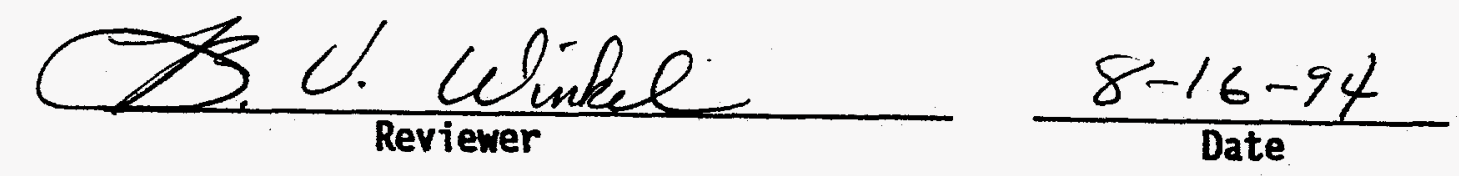

- REVIEWED FROM VIEWPONT OF SOFTWARE (SASST) USER. 


\title{
SASSI System Software Configuration
}

\author{
EO Weiner
}

August 1994

\section{INTRODUCTION}

The SASSI (System for Analysis for Soil-Structure Interaction) computer program was obtained by WHC from the University of California at Berkeley for seismic structural analysis of complex embedded building configurations. SASSI was developed in the 1980's by a team of doctoral students under the direction of Prof. J. Lysmer. The program treats three-dimensional soil-structure interaction problems with the flexible volume substructuring method. In the 1970's, the same organization developed the FLUSH program, which has achieved widespread international usage in the seismic analysis of structures. SASSI consists of nine modules, each of which are to be run as a separate execution.

The SASSI source code, dated 1989 and identified as a Cray version, was put up on the RL Cray XMP/232 Unicos system in 1991. That system was removed at the end of 1993, and SASSI is now installed on the LANL Cray YMP systems.

SHAKE is a much simpler program that solves the free-field soil problem by iteration with strain-dependent soil properties. Current practice uses SHAKEderived soil properties as fixed input to SASSI. The SHAKE PC version was obtained from the Earthquake Engineering Research Center (EERC), University of California, Berkeley, in 1990. It was installed on an $80386 \mathrm{PC}$ and the RL Cray, and it is included with the SASSI configuration. An updated version, SHAKE91, was obtained in April 1994 from the same source. Both SHAKE and SHAKE91 have been installed on a 486 PC, the SECC sgi3 workstation, and the LANL Cray YMP systems.

A short auxiliary program HOUSEPLT was written to transiate the SASSI. HOUSE module input to ANSYS version 5.0 (ANSYS 1993) PREP7 input suitable for mesh plotting. This enables the engineer to obtain a graphic representation of his model that is not otherwise possible. Filters TRFILTER, HFILTER and SMFILTER were written to limit unneeded volumes of output from ANALYS, HOUSE, STRESS and MOTION.

The purpose of this document is to demonstrate compliance with WHC-CM-3-10 (WHC 1993). 
IMPACT LEVEL

Impact level 2 was previously assigned to SASSI. SQ is considered the current appropriate level.

\section{DOCUMENTATION}

SASSI: User manual (Lysmer 1991)

Theoretical manuals (Lysmer 1981, Bechtel 1991)

Validation manual (Bechtel 1990)

SHAKE: User manual (Schnabel 1972)

SHAKE91: User manual (Idriss 1992)

HOUSEPLT: Appendix A

\section{SOFTWARE DEVELOPMENT PLAN}

SASSI was developed at the University of California over the 1979-1989 timeframe, and it is off-the-shelf software. The theoretical manuals provide development information.

\section{VERIFICATION}

Design verification is considered as conducted by the developers during the development process. SASSI is off-the-shelf software obtained after development.

\section{VALIDATION}

A validation report (Bechtel 1990) was made available by Savannah River Site (SRS) personnel. It is organized into eighteen example problems, each of which may be broken down into several cases. The examples are described briefly as follows.

\section{Example Description}

1 Free-field analysis of halfspace; vertically propagating

SP and $P$ waves.

2 Containment building model with bricks and beams; uses COMBIN.

3 Rigid disk on surface subjected to a trapezoidal pulse.

4 Impedances for circular foundation on layered soil system.

5 Scattering response of a rigid massiess cylinder fully embedded; subjected to vertical SV-wave and horizontal SH-wave.

6 Surface foundation consisting of both rigid and flexible components.

7 Scattering response of an embedded massless rigid cube with an inclined wave.

8 Series of simple problems using currently available elements. Displacement solutions.

9 Series of simple problems using currently available elements. Stress solutions.

10 Coupled building analysis, two dimensional. 
11 Scattering response of a rigid massless cylinder fully embedded in a layered system.

12 Impedance response of a rigid fully embedded cylinder.

13 Flexible plate on surface subjected to machinery loads.

14 Compliance functions of a strip footing on the surface of a viscoelastic halfspace and a layered soil system.

15 Compliance functions for a rigid circular surface foundation in horizontal, vertical, rocking and torsional modes.

16 Rigid massless cylinder fully embedded and subjected to Rayleigh wave input.

17 Scattering response of a rigid square surface foundation subjected to SH-, SV-, P-waves and Rayleigh waves.

18 SSI response of a stick model on a rigid disk with the control point at grade level.

Collectively, the examples require 174 executions of the nine SASSI modules. Solutions are compared with closed form solutions, open literature, and alternate validated program results. The validation problems have been run and checked on the DOE Savannah River Cray XMP computer which is similar to the RL and LANL Crays. The extent of SRS module testing is as follows:

\begin{tabular}{|c|c|c|c|}
\hline Module & Executions & $\begin{array}{l}\text { Source } \\
\text { Lines }\end{array}$ & Module Description \\
\hline SITE & 30 & 2800 & Free field site response solution. \\
\hline POINT2 & 4 & 1200 & Two dimensional version of POINT3. \\
\hline POINT3 & 20 & 1900 & Point load solution needed for inter- \\
\hline HOUSE & 31 & 4100 & $\begin{array}{l}\text { Stiffness and mass matrices for structure } \\
\text { and excavated soil. }\end{array}$ \\
\hline MOTOR & 26 & 350 & $\begin{array}{l}\text { Load vector corresponding to external } \\
\text { forces, e.g., machinery. }\end{array}$ \\
\hline ANALYS & 49 & 3100 & $\begin{array}{l}\text { Formation of impedance matrices and } \\
\text { loads; solution for transfer functions. }\end{array}$ \\
\hline COMBIN & 1 & 270 & $\begin{array}{l}\text { Combination of two ANALYS frequency sets } \\
\text { into one. }\end{array}$ \\
\hline MOTION & 8 & 1700 & $\begin{array}{l}\text { Time histories of accelerations, } \\
\text { calculation of response spectra. }\end{array}$ \\
\hline STRESS & 174 & 2000 & $\begin{array}{l}\text { Evaluation of maximum stresses and } \\
\text { strains in structural elements. }\end{array}$ \\
\hline
\end{tabular}

The scope of the validation effort shows good balance.

Example 2, Cases 1-5, along with Example 9, Case 5, were adopted as the in-use testing set, because they exercise all the modules. In addition, Examples 5 , 9,11 , and 17 were run on the RL Cray, and the results compared favorably with the validation report.

SASSI installation on the INEL Cray started in late 1993 as a replacement for the RL Cray. It passed the in-use test. However, a waste tank model produced anomalous results if a single block was used for the structural stiffness 
matrix in the house module. Testing on other Cray sites and workstations could not reproduce the anomalous results. Installation at INEL was then dropped in favor of LANL. A precise cause of the anomalous results at INEL was never identified. Consequently, other than the extensive testing that followed, no claim is made that a similar incident cannot happen again.

At LANL, the in-use tests and two waste tank models (including the one with anomalous results at INEL) proved satisfactory. Considering the INEL experience, however, it was decided to run all 18 test cases from the BechtelSRS validation report and compare with RL output obtained by Kaiser Engineers Hanford (KEH) in an effort following the RL Cray installation (Luo 1994). Testing with these cases was based entirely on computer-differencing of test and reference files and proved satisfactory.

Hadjian (1989) reports on an experiment designed to evaluate and synthesize results of several soil-structure interaction analyses based upon measured responses of a $1 / 4$ scale containment model in the quake-prone Lotung region of Taiwan. Results of this reference indicate that deconvolution anaiyses using equivalent linear methods and assuming vertically propagating shear waves captured the essential features of variations of ground motion with depth. Considering recorded results with the model containment, several analyses methods were compared by Tang (1989). SASSI was employed by two organizations in this comparison, and it proved to be as good as or better than any other method in its prediction capability.

Finally, two in-house projects (Giller 1991, Winkel 1991) used both the SASSI and FLUSH systems for analyzing embedded and underground structures. The reasonable comparisons between the two systems added to the confidence in the SASSI system.

SHAKE has been widely used in the industry since its introduction in the early 70 's. The test input cases provided by EERC with the source were run and checked satisfactorily with the output provided. In addition, a soil profile typical of the Hanford site was analyzed with the Fc correlation (see Appendix A) to a $0.2 \mathrm{~g}$ Newmark-Hall time history appropriate to the response spectrum given in SDC4.1, Rev 11 (Hanford, 1989). The results compared well with FLUSH results (Winkel, 1991). SHAKE9l was given similar testing.

HOUSEPLT was satisfactorily tested with nine of the HOUSE module validation problems. Testing included ANSYS plots with all useful plotting options; details may be found in Appendix A. Users should check usage of the filters TRFILTER, HFILTER, and SMFILTER based on normal vs truncated output.

The reliability of the LANL/SASSI system demonstrated by the above discussions is considered adequate for impact level 2 software to be used by qualified engineers.

\section{CONVERSION}

The SASSI version as received was for a Cray is system. The effort to convert to the Cray XMP under the Unicos operating system was minimal, being restricted to sensing what memory is available to the user and allocating it to blank common. SHAKE and SHAKE9l conversions were also minor, being restricted to character variables, alignment considerations and formatting. 
Details of the conversions are given in Appendix B.

CONFIGURATION MANAGEMENT

Installation:

SASSI - LANL Cray YMP (gamma, zeta machines)

SHAKE91, SHAKE - LANL Cray, DOS PC, SECC sgi3 w/s

HOUSEPLT - LANL Cray, DOS PC, SECC sgi3 w/s

User access:

LANL Cray: Normal Cray access plus copy of program file from CFS to temporary directory. See Appendix A.

DOS PC: Through the user's PC to server area IIwhc240 \special. See Appendix A.

SECC: Normal SECC access plus copy of program file from CFS to temporary directory. See Appendix A.

Custodian: EO Weiner

User identification:

Users should identify themselves to the custodian and indicate the installation to be used. They should also indicate when usage is no

longer anticipated.

Files:

Source files: *.f (Cray, SECC), *.f (PC) and iclim.c.

Main executable files:

site, point2, point3, house, motor, analys, motion, combin, and stress.

Auxiliary executable files (see Appendix A):

shake, shake91, houseplt, trfilter, hfilter, smfilter, rdtable, fs

Configuration files:

sassila.res: script - Cray compile and load sources

sassila.tst: script - Cray in-use testing

sassiws.res: script - sgi3 compile and load sources

sassiws.tst: script - sgi3 in-use testing

sassi.usr: custodian's list of users

sassi.log: custodian's log

notes: custodians notes

sassires.bat: DOS batch - compile and load sources on PCs

sassitst.bat: DOS batch - in-use testing on PCs

In-use testing:

e2c*d: example 2 inputs, SRS validation

e9c*d: example 9, case 5 inputs, SRS validation

*.inp, *.out: test $i / 0$ files. sassi.out is the concatenation

Other: of representative e[29]c* outputs from tests

nsbtest: dynamic memory example

valid/: validation problems

*.doc: excerpts from user's manuals

Primary storage:

Source, in-use testing, configuration files (no executabies):

LANL CFS /eow/sassi.tar.Z 
Program files (executables, examples, *.doc files):

LANL CFS /eow/sassiusr.tar (requires general read access)

Backup storage:

Source, in-use testing, configuration files (no executables):

RL CFS/w91428/sassi.tar.Z

Custodian's PC, dir=c: \sassi

Program files (executables, examples, *.doc files):

Copy and recompile from LANL or RL source files

Other storage:

Validation problems:

RL CFS /w91428/sassi/bvalinp.tar.Z

Custodian's PC c: Isassilvalid

Error reporting and modifications:

All errors and anomalies as well as modification requests should be directed to the custodian in writing. Error reports and program revisions are made by the custodian with the approval of his manager. They are announced by distribution to a list of users maintained by the custodian. Changes to the programs are tested and documented by the custodian, in a manner conforming to WHC-CM-3-10.

Custodian log/listing

The custodian maintains a log of significant events such as error reports, resolutions, modifications, changes in operating environment or configuration. Source listings and test outputs are maintained by the custodian on his PC, dir=c: \sassi.

Restoration

Restoration (compile and load) is performed by the custodian. For Cray restoration, sources may be copied from the permanent storage (CFS /eow/sassi.tar.Z), uncompressed, and untarred to a Cray disk directory, typically in the custodian's temporary area. Script sassila.res then compiles and loads the sources, establishing a sassiusr program directory. Sources and other user-unnecessary material are removed by the custodian with a script cleanup.scr. The sassiusr should be stored on CFS for user access. Access rights for the user should be established with the cfs command: $\bmod$ sassiusr aval=0/r/-/s. In-use testing can be with sassila.tst. For PC restoration to k:, sassires.bat can be run by the custodian.

In-use Testing

In-use testing is to be conducted with changes in operating environment or configuration. The Cray and SECC modules are tested by the custodian, and the PC modules are tested by the individual user on his machine. Script and batch files are provided: sassila.tst for the Cray, sassiws.tst for sgi3 and sassitst.bat for the PC. In these scripts, *.inp files are input test files, and *.out files are reference output files. In-use testing consists of running *.inp files with the current modules after restoration and differencing the resulting outputs against the reference outputs. Differences sent to *. dif files may show version number and timing differences, etc. The PC modules typically have reference outputs from the SECC executions, and they may show minor 
roundoff and timing differences which are acceptable. Testing on the server $P C$ is done initially by the custodian. See Appendix $C$ for details. With satisfactory results, the custodian should replace the reference outputs with the newly generated results on the server. Testing by the user on his own machine by copying the PC server directory $k$ : leow $\backslash$ sassi to his own directory and executing sassitst.bat should then produce a close match.

Scripts

Scripts listed in this configuration report provide detail information on how the SASSI system is configured. The custodian insures that details of the scripts are current.

File transfers

Moving files such as sassi.tar.Z and sassiusr.tar with FTP should always be done in the binary mode. Such moves may be necessary with RL CFS as well as the Internet file transfers offsite.

\section{REVISIONS}

$\begin{array}{lllll}\text { Version } & \text { Program } & \begin{array}{l}\text { Compiler } \\ \text { Version }\end{array} & \begin{array}{l}\text { Operating } \\ \text { System }\end{array} & \text { Revision } \\ \text { cft77 } 4 / 3 / 91 & \text { SASSI } & \text { cft77 6.0.2.0 } & \text { Unicos 7.0 } & \text { Initial } \\ \text { cft77 } 4 / 26 / 91 & \text { SHAKE } & \text { cft77 } 6.0 .2 .0 & \text { Unicos 7.0 } & \text { Initial } \\ \text { cft77 } 6 / 7 / 94 & \text { SHAKE91 } & \text { cft77 6.0.2.0 } & \text { Unicos 7.0 } & \text { Initial } \\ \text { cft77 } 9 / 7 / 91 & \text { HOUSEPLT cft77 } 6.0 .2 .0 & \text { Unicos 7.0 } & \text { Initial }\end{array}$

Version identification is included in the program sources and the printed output of each application. SHAKE, SHAKE91 and HOUSEPLT modules available on the $P C$ are identical to the Cray versions. The PC copies are compiled with Lahey f771 version 4.01 with the DOS 3.31 operating system.

\section{REFERENCES}

WHC, 1993, "Software Practices", WHC-CM-3-10, Re1 0, 1-31-93.

DeSalvo, G.J. and R.W. Gorman, 1989, "ANSYS Engineering Analysis System User's Manual", for revision 4.4, Swanson analysis Systems, Inc, , Houston PA 15342, 1989.

Lysmer, J. et a1, 1975, "FLUSH - A Computer Program for Approximate 3-D Analys is of Soil-Structure Interaction Problems", Report No. EERC 75-30, College of Engineering, University of California, Berkeley CA, November 1975, available from NTIC as PB 259332.

Hadjian, A.H. et al, 1989 "Soil-Structure Interaction Lotung Experiment: Prediction Evaluation Basis", SMiRT 10, vol K/1, p 187, August 1989

Idriss, I.M., 1992, "User's Manual for SHAKE91", program and code availabie from NISEE, Earthquake Engineering Research Center, University of California, Berkeley, CA

J. Lysmer et a1., 1991, "SASSI User's Manual", Bechtel Corp., San 
Francisco, 1991.

J. Lysmer et a1., 1981, "SASSI - A System for Analysis of Soil-Structure Interaction", Report No. UCB/GT/81-02, Geotechnical Engineering, University of California, Berkeley, April 1981.

Bechte1, 1991, "SASSI Theoretical Manual", Bechtel Corp., San Francisco, 1991.

Bechte1, 1990, "SASSI Validation Report", prepared for Westinghouse Savannah River Co., Aiken, SC by Bechtel Savannah River, Inc., 1990.

Tang, Y.K., 1989, "Proceedings: EPRI/NRC/TPC Workshop on Seismic Soi1Structure Interaction Analys is Techniques Using Data from Lotung, Taiwan", NP-6154, Research Project 2225, EPRI, March 1989.

Bathe, K.-J. et al, 1974, "SAP IV - A Structural Analysis Program for Static and Dynamic Response of Linear Systems", Report No. EERC 7311, College of Engineering, University of California, Berkeley CA, April 1974.

Schnabel, P.B. et al., 1972, "SHAKE - A Computer Program for Earthquake Response Analysis of Horizontally Layered Sites", Report No. EERC 72-12, Earthquake Engineering Research Center, University of California, Berkeley CA, December 1972.

Hanford, 1989, "Arch-Civil Design Criteria, Design Loads for Facilities", HPS-SDC-4.1, Rev 11, May 1989.

Giller, R.A. and E.0. Weiner, 1991, "Soil Structure Interaction Analysis for the Hanford Site 241-SY-101 Double-Shel1 Waste Storage Tanks", WHC-EP-0504, Westinghouse Hanford Co., Richland WA, September 1991. 
WHC-SD-GN-CSWD-30036 Rev 1

Page A-1

Appendix A. Runstream Examples and User Information 
Appendix A. Runstream Examples and User Information

\section{SASSI SCRIPT EXAMPLE}

The following LANL PROD script runs the example cases 1 and 2 shown in Table A.2-3 of the validation manual (Bechtel, 1990). It demonstrates how the user should obtain the executables from CFS.

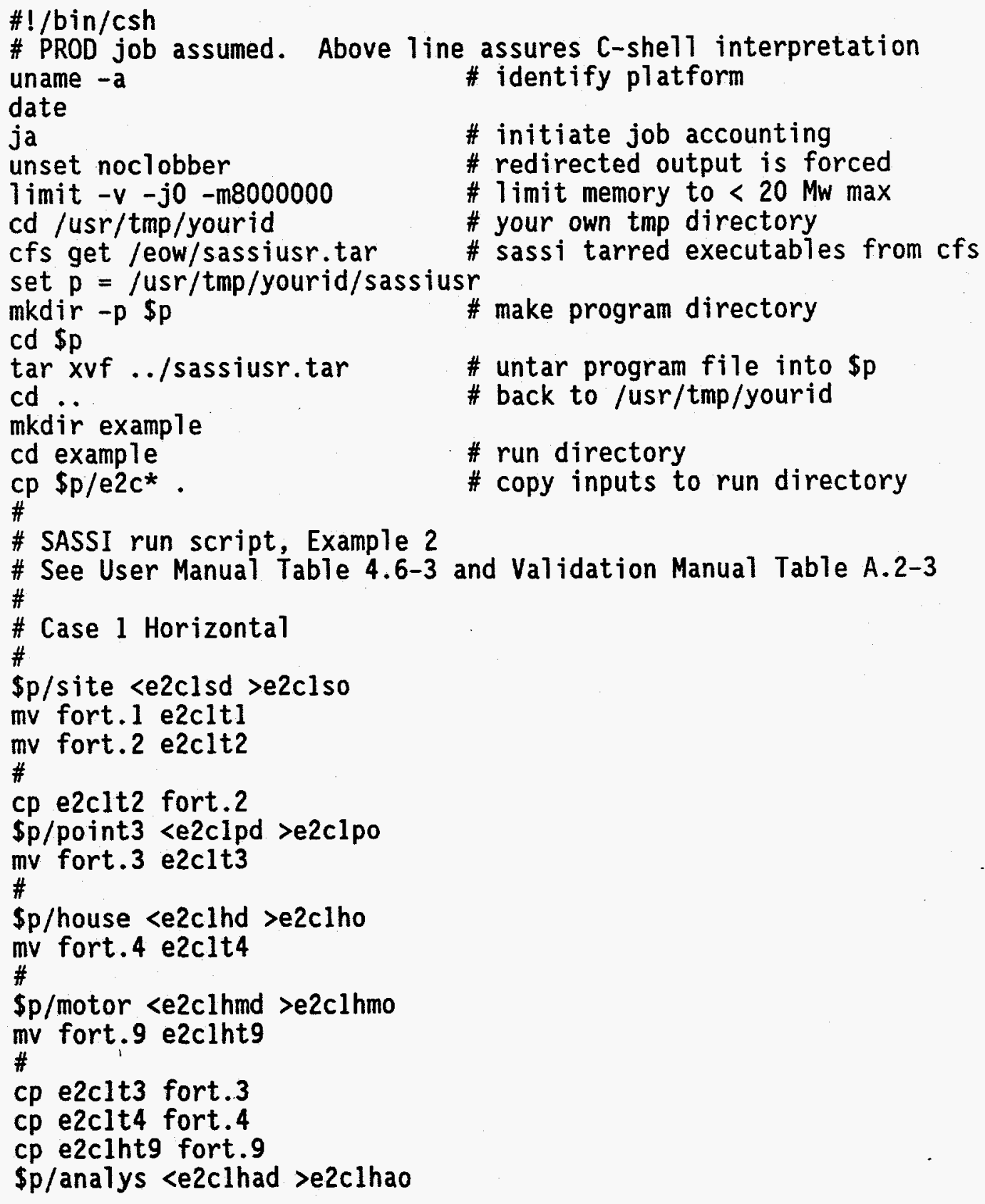




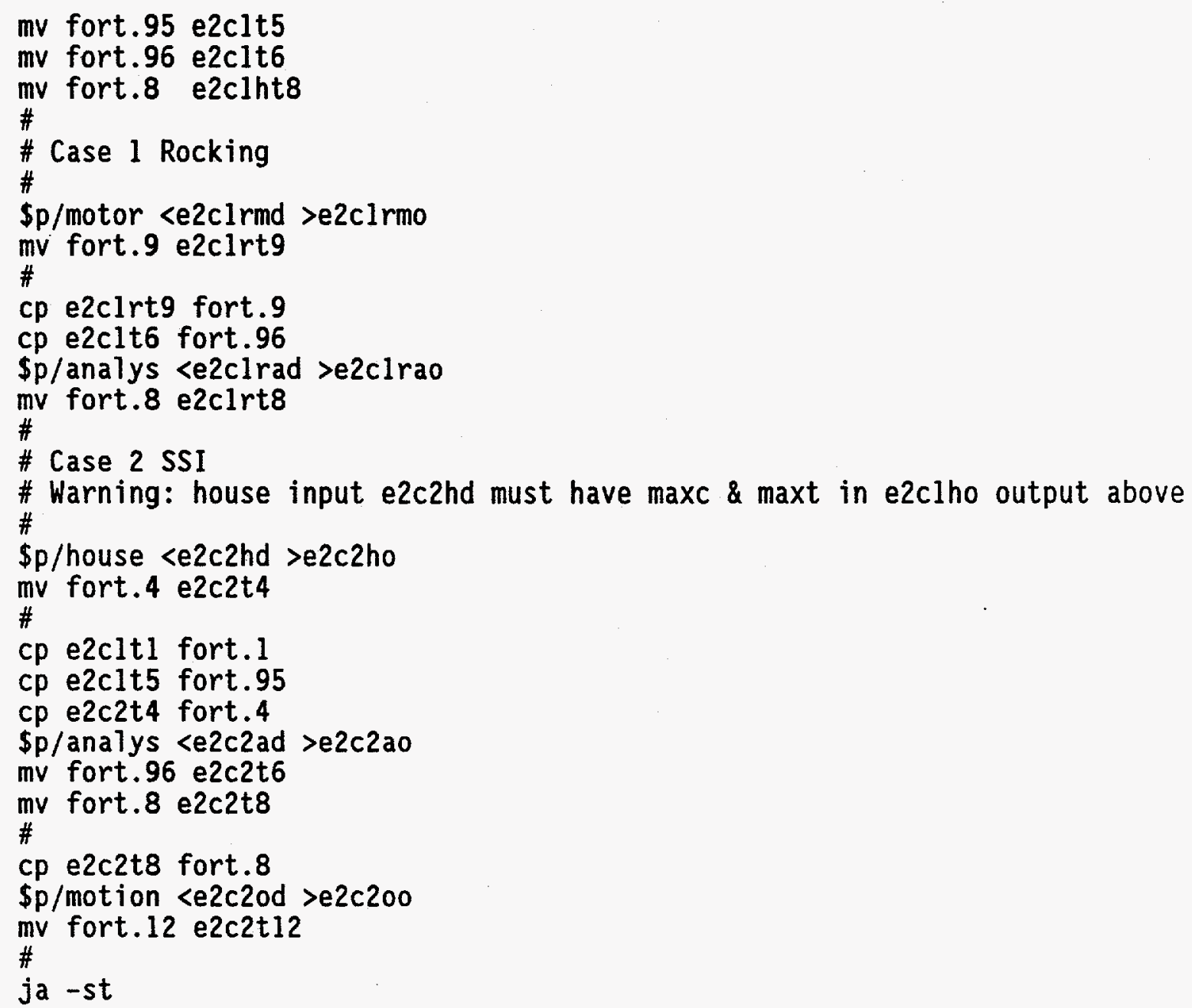

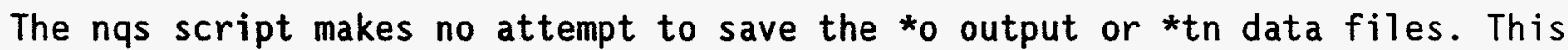
should be done with CFS commands in the script. LANL Unicos and other appropriate documentation should be consulted for details.

Assuming the above script is jobl, submit the job with:

gamma\% prod

Prod $>$ submit jobl $t=180$ pr=9 $s=*$ ta=g

Prods end

Note that the target machine (gamma) is specified with $t a=g$ and that the temporary run area is specified in the script as/usr/tmp/yourid/example. The user can expect to find output files there up to 48 hours later. If the target machine were left open and the temporary area not specified, it is not clear that unsaved files could be recovered. SASSI is only tested on gamma and zeta, and usage should be restricted to those machines. The $t=180$ entry denotes a limit of $180 \mathrm{CP}$ minutes, and $\mathrm{pr}=9$ seems to be a standard priority. Standard output is placed in the user's home directory. The LANL PROD documentation should be consulted for details of submitting production runs.

ON-LINE DOCUMENTATION 
Excerpts from the user's manuals have been placed on-line as *.doc files on the Cray, sgi3 w/s and PC server with the program files. Some of the seldom used auxiliaries such as fs are not compiled on some of the platforms. In such cases the *.doc file is the source file which the user may compile.

\section{DATA FILES}

Data output files like e2clt4 appear as fort. 4 after execution of the first HOUSE module. The exception to the rule is: files that should show up as fort. 5 or fort. 6 (e.g., e2clt5 from ANALYS) show up as fort.95 and fort.96. It is the user's task to manipulate and save the proper files in accordance with the user manual.

Recommended current practice is to rename output fort. $n$ files needed later as (for example) e2cltn, and then copy it back to fort. $n$ when needed as input. It might be possible to skip the rename/copy processes. For example, fort. 4 from HOUSE should be good for ANALYS, because modification of fort. 4 by the system has not been noted unless declared in the user manual.

\section{RESOURCE ESTIMATES}

ANALYS CPU, file size and memory estimators are based on a $3 \mathrm{hr}$ run:

$$
\begin{aligned}
& \text { CPU (sec) }=(\text { NUMGP*NDOF) } * * 3 * N F * S C P U \\
& \text { TAPE5 (words) }=(\text { NUMGP*NDOF) } * * 2 * N F * S 5 \\
& \text { MEM (words) }=(\text { NUMGP*NDOF)**2*SMEM }+300000
\end{aligned}
$$

where

$$
\begin{aligned}
& \text { CPU }=\text { ANALYS cpu estimate, sec } \\
& \text { TAPE5 }=\text { tape5 size estimate, words } \\
& \text { MEM }=\text { HOUSE and ANALY common block requirement, words } \\
& \text { NUMGP }=\text { number of interaction nodes } \\
& \text { NDOF }=\text { number of degrees of freedom per interaction node } \\
& \text { NF }=\text { number of frequencies } \\
& \text { SCPU }=\text { cpu scale factor }=.4 \mathrm{e}-6 \\
& \text { S5 }=\text { tape5 scale factor }=3 \\
& \text { SMEM }=\text { memory scale factor }=2
\end{aligned}
$$

TAPE6 sizes are about like TAPE5, and the other tapes are much smaller. The ANALYS module dominates the cpu consumption. The CPU estimate is known to be low for small jobs, by a factor of 1.5 for a 10 min job. The other modules (SITE, POINT3, HOUSE, etc) are much quicker. See the memory expansion discussion below for HOUSE memory.

As an example,

$$
\begin{aligned}
& \text { NUMGP }=469 \\
& \text { NDOF }=3 \\
& \text { NF }=10
\end{aligned}
$$

so

$$
\mathrm{CPU}=(469 * 3) * * 3 * 10 * .4 \mathrm{e}-6=11140 \mathrm{sec} \quad \text { vs } 11100 \mathrm{sec} \text { actual }
$$


TAPE5 $=(469 * 3) * 2 * 10 * 3=59$ Mword $=480$ Mbyte

MEMORY $=(469 * 3) * * 2 * 2=4.0$ Mword

In smaller jobs, one may consider using the maximum core available, especially if it results in single block stiffness storage per HOUSE block storage information output. This may improve the turnaround, but not likely the CPU consumption. The large TAPE5/6 size should be noted. It may cause permanent file storage problems and unneeded costs. A rerun of ANALYS as opposed to a restart should be considered along with the likelihood of a restart need.

\section{MEMORY EXPANSION}

Memory expansion in HOUSE and ANALYS is fairly straight forward as the programs detect the maximum available (up to $20 \mathrm{Mw}$ ) and back off $4.7 \mathrm{Mw}$ with house and 3.7 Mw with analys for a maximum blank common. The 7 imit() command may be used to reduce the maximum memory available in view of the memory time integral contribution to cpu charges or user requirements to place limitations on the SASSI matrix blocking procedure.

In doing restarts with HOUSE and ANALYS it was possible for the user to get trapped in the RL system. A HOUSE run would block TAPE4 to the maximum size possible. Then ANALYS used this TAPE4 as input, and blocked TAPE5 the same way. Then the user changed the superstructure and did another HOUSE run. He knew that he had to force HOUSE to use the old blocking with MAXT and MAXC so that the ensuing ANALYS mode 2 run would read TAPE4 and TAPE5 with the same blocking. One would expect the restart HOUSE run to fail, because the model is usually larger. Instead the ANALYS mode 2 run fails with a small shortage of core. It is hoped that the smaller HOUSE blank common (VS ANALYS) will prevent the problem from occurring at LANL. If not, the user might make it a policy to 1 imit() memory somewhat as a practice and then increase it for the ANALYS run if the problem occurs.

The need for MUSE input in the HOUSE module is not understood. Input of MUSE $>0$ appears to interfere with user input of MAXT and MAXC required to insure coordinated block sizes data files. The default MUSE input is recommended at this time.

\section{EMBEDDED BLANKS}

The CFT77 options used to compile SASSI include the default BN i/o option which condenses out embedded blanks in integer and real input. An input field with 1111 reads 1111 instead of 110101 , so it is suggested that the user put in the zeros in case the program reads it with (i6) instead of (6i1). A completely blank field is still read as a zero.

\section{HOUSE GENERATION}

Examples of node and element generation in HOUSE may provide some clarification to the user manual.

The node card sequence (start-end cards)

$\begin{array}{llllllll}C & 5 & 1 & 1 & 5.0 & 0.0 & 10.0 & 1 \\ \mathrm{~S} & 9 & & 1 & 9.0 & 0.0 & 14.0 & 2\end{array}$


produces

$\begin{array}{lllllll}\mathrm{C} & 5 & 1 & 1 & 5.0 & 0.0 & 10.0 \\ \mathrm{C} & 7 & 1 & 1 & 7.0 & 0.0 & 12.0 \\ \mathrm{~S} & 9 & & 1 & 9.0 & 0.0 & 14.0\end{array}$

Thus, intermediate nodes are generated using the end card increment and the start card boundary conditions and coordinate system. The last card boundary conditions are not generated from the start card; they are read from the end card. The user will probably always use the same coordinate system on both the start and end cards. Note how the example works when they are different.

The beam element sequence

$\begin{array}{lllllll}10 & 12 & 14 & 120 & 1 & 1 & 5 \\ 13 & 22 & 29 & 120 & 1 & 1 & 2\end{array}$

produces

$\begin{array}{llllll}10 & 12 & 14 & 120 & 1 & 1 \\ 11 & 17 & 19 & 120 & 1 & 1 \\ 12 & 22 & 24 & 120 & 1 & 1 \\ 13 & 22 & 29 & 120 & 1 & 1\end{array}$

Thus, intermediate elements are generated from the start card using the start card increment for node numbers, and each intermediate element is generated. The end card nodes are not generated; they are read from the end card.

\section{BASEMENT STRUCTURE AND INTERACTION NODES}

The topic of interaction nodes and basement structure needs special attention. It was found that an interior basement wall physically not connected to the actual soil did not respond as expected as an oscillator excited at its base. The wall nodes were all identified as interaction nodes. The problem was corrected by creating separate non-interaction nodes for the wall structure away from the base, and this correction was verified as appropriate with one of the developers at Bechtel. Interaction nodes are used to model excavated soil, and their separation requirements are governed by soil properties. Basement structural nodes identified as interaction nodes apparently should have stiff paths to the actual soil. Clearly all exterior wall nodes should be interaction nodes.

\section{OTHER THINGS NOTED}

- Interaction nodes in HOUSE need to be precisely on layer interfaces. The user has to plan his grid accordingly. The recommended way is to use a simple grid with not too many layers. Then SHAKE9l can be run with those same layers, and the resulting data can be fed into HOUSE and SITE.

- SYMMETRY: The user's manual might lead one to believe that simply declaring a symmetry plane will take care of the boundary conditions. Apparentiy, the program will provide them for the soil impedence matrix, but not for the structure or excavated soil. The user must definitely 
provide them for the structure, and it appears prudent to provide them for the excavated soil. Generally, symmetric boundary conditions zero out one translational and two rotational dofs (degrees of freedom) that produce deformation out of the plane. Asymmetric boundary conditions zero out two translational and one rotational dof that produce deformation wholly in the plane.

- SPRINGS: There is no obvious way to model the normal point-to-point truss with the spring element. An alternative is to use beam elements with member end releases (do NOT release BOTH torsional dofs).

- TRIANGULAR ELEMENTS: P1ate/shell triangular elements are entered by omitting the fourth node. Quad2d triangular elements have the fourth node equal to the third.

- TRIANGULAR SHELL ELEMENTS: Sections C.10.3.3 and H.3.3.2 of the user's manual describe the plate element local axes. The triangle in the figure of H.3.3.2 shows the $K$ - and L-nodes coalesced. Instead, the $L$-node should be coalesced with the I-node: the L-label should be moved next to the I-label. Then the orientation of the local axes in the figure will be consistent with the definition in C.10.3.3. Note that bending results should be interpreted as occurring at the $K$-node. Membrane results are constant over the triangle and would be better interpreted at the centroid.

- NPAR(1) essentially defaults to 1 in HOUSE

- MOTION: Printing several response spectra with MOTION is a good way of getting a quick overall view of the results. MOTION is cheap. If time histories are punched (per user manual), they are also printed, and this just gets in the way of the plotted response spectra. The user might consider two separate runs in this case.

- SITE: Aborts with a 90 degree incidence angle. Use 89 degrees.

- STRESS with 2D quads will print T-OCT if requested with the fourth key. The manual does not show this, most likely because the programming (in routine oct4) looks bad: Toct $=(S x x+S z z+T x z) / 3$. Asking for Toct with element 4 is definitely not advised.

Users are reminded to contact the custodian to insure they are on the user list along with initial and final dates of usage.

\section{PC AND WORKSTATION MODULES}

In addition to the Cray, SHAKE, SHAKE91 and HOUSEPLT and the filter modules are available on the PC and the SECC sgi3 workstation.

To access the PC versions, key in

connect k: IIwhc240 \special

copy k: \eow \sassi\*.* c: \sassi

The individual programs are run on the user's machine with redirection, e.g., 
c:

cd Isassi

shake91 <input >output

Do not run the program on the shared area of the file server. The PC shake91 version runs 20 times as slow as on the workstation.

It is the responsibility of the user to conduct $P C$ in-use testing to insure the system is working properly on his particular machine. The testing procedure is described in the configuration management section of this report, and the batch file sassitst.bat in k: leow this testing.

SASSI auxiliary programs SHAKE91, SHAKE and HOUSEPLT are available on the SECC workstation sgi3. Access to these programs is through the custodian's

directory in CFS. The users should store and run them on their own temporary directories in the workstation, e.g.,

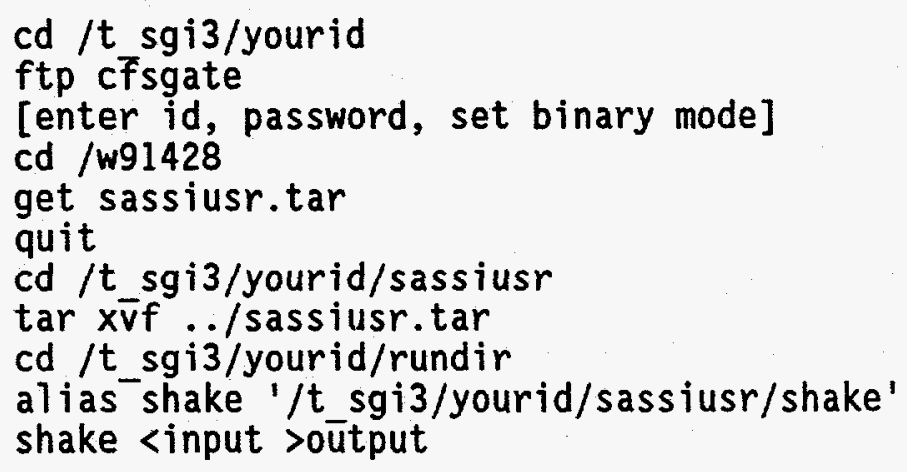

\section{SHAKE91}

This program was favored over the old SHAKE, because it provided for more soil types and layers, and it provided a more direct way of entering soil properties. Printer plots along with some seldom-used options are no longer found in SHAKE91. It should be noted that some old SHAKE input is still in effect, even thought the SHAKE91 manual does not mention it. Don't throw out the old SHAKE manuals. In particular,

- Option 2 line 1 MWL input in cols $11-15$ is not in the SHAKE91 manual. Omitting it means that $M W L=0$ and amounts to putting the water table at the top of layer 2. The total pressure in the output has water hydro-pressure removed. It has no other effect on other ouput, however. The user can input MWL to get the total pressure expected.

- Option 2 line 2+ NLN input in cols 11-15 is also missing in the manual. It will produce sublayers within the one-line layer.

Changes pertinent to the user:

- Usage is like SHAKE; after copying similar to SHAKE described above, the program is executed with:

$$
\text { shake91 <input >output \# } t / h \text { output on file "punch" }
$$


- Added code to take Poisson's ratio input in Option 2 line 2+ in cols 66-75 for each layer and produce iterated soil property output suitable for SASSI input. User must insure consistency of units.

Other things noted:

- Option 9 (compute response spectrum) has input for the acceleration of gravity, which seems unusual since the program has a built-in value of $32.2 \mathrm{ft} / \mathrm{sec} / \mathrm{sec}$. The option 9 input seems to affect only the spectral displacement and velocity output units of the same option. If the user wanted the spectral velocity in $\mathrm{cm} / \mathrm{sec}$, then $\mathrm{g}=981$ would be appropriate.

SHAKE

The SHAKE program solves the free-field soil problem with iteration on strain-dependent soil properties. Common practice uses SHAKE-derived soil properties as fixed input to SASSI. The FLUSH program has the SHAKE capability built into it; SASSI does not. Punch output is to be found on the named file "punch". The test problems take a little over a minute on a Compaq $386 / 20 \mathrm{e}$. The PC must have a $80 \mathrm{n} 87$ math coprocessor. The time history sequence check was disabled.

The treatment of units in the manual is delicate at best, especially for sand. The user should refer to the manual example input and output to insure his understanding of the Option $2 \& 8$ processes. It is suggested that option 8 input be used to enter $K s=G / G_{0}$ and beta vs strain as was the practice with FLUSH. Here, $G$ and Go are the shear moduli at strain and low strain, respectively. The low strain shear modulus is then entered via Fs for sandy soil in Option 2 with

$$
\begin{aligned}
& \text { Fs }=\text { Go / sqrt }(\mathrm{Sm}) \\
& \text { Go }=10 w \text { strain shear modulus, ksf } \\
& S_{m}=(1+2 * \text { sko }) / 3 * \text { head } \\
& \text { head }=\text { overburden pressure, psf } \\
& \text { sko }=\text { coefficient of earth pressure at rest, default }=.45
\end{aligned}
$$

The (c) note in Option 2 has a factor of 1000 in the Gs formula. It appears that the program internally applies this factor and that the user should not. The user should think in terms of ksf input for the shear modulus. One could view Fs as an correlation tool: a representative value should suffice unless there is evidence of drastic changes in soil properties. See Reference Al. An alternative would be to use the clay correlation $\mathrm{Fc}=\mathrm{Go}$ which is more like FLUSH practice. However, the sand correlation tends to produce smoother iterated modulus profiles in large layers with constant Fs values, because the sqrt(Sm) relation tends to soften the soil near the top of the layer, while a constant Go produces increasing iterated $G$ values toward the top of the layer. The user is cautioned about using the sand correlation near the surface where the control motion is specified. Soft soil under the control point tends to attenuate the free field motion at depth, and this could lead to unconservative excitation for embedded structures.

Fs input example: 


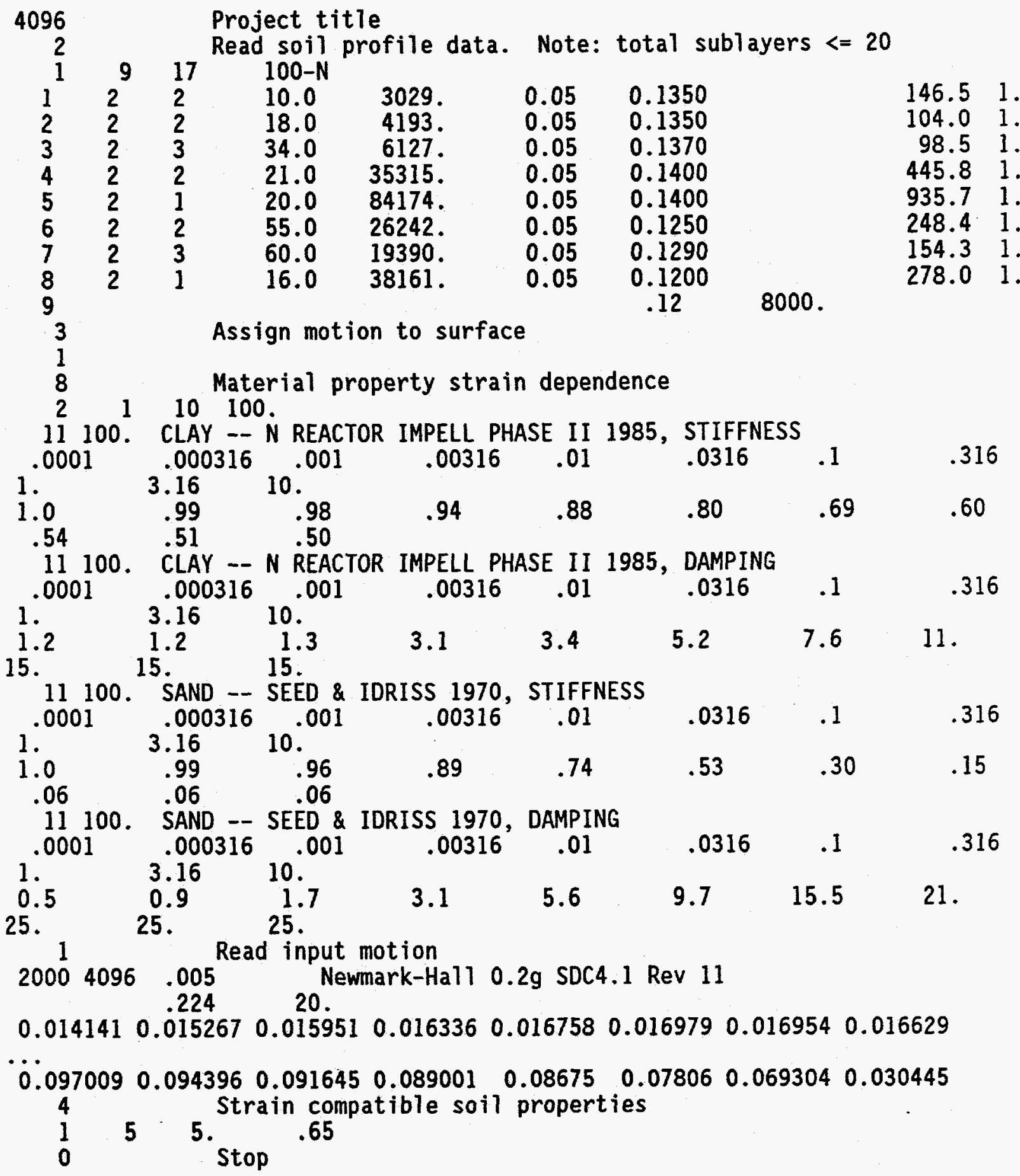

Fc input example (models sand profile with Fc):

$$
\begin{aligned}
& 4096 \quad \text { Project title }
\end{aligned}
$$

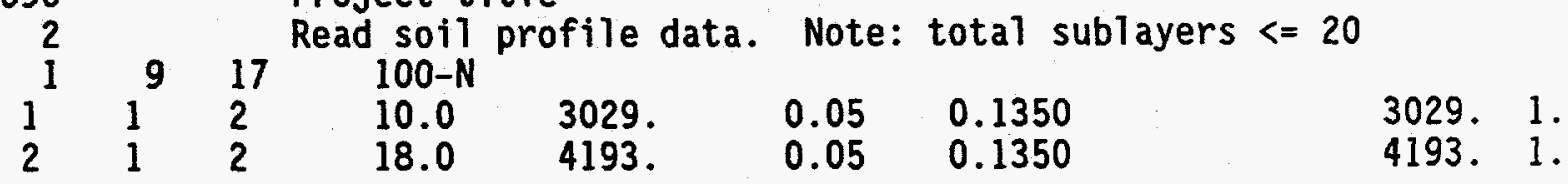




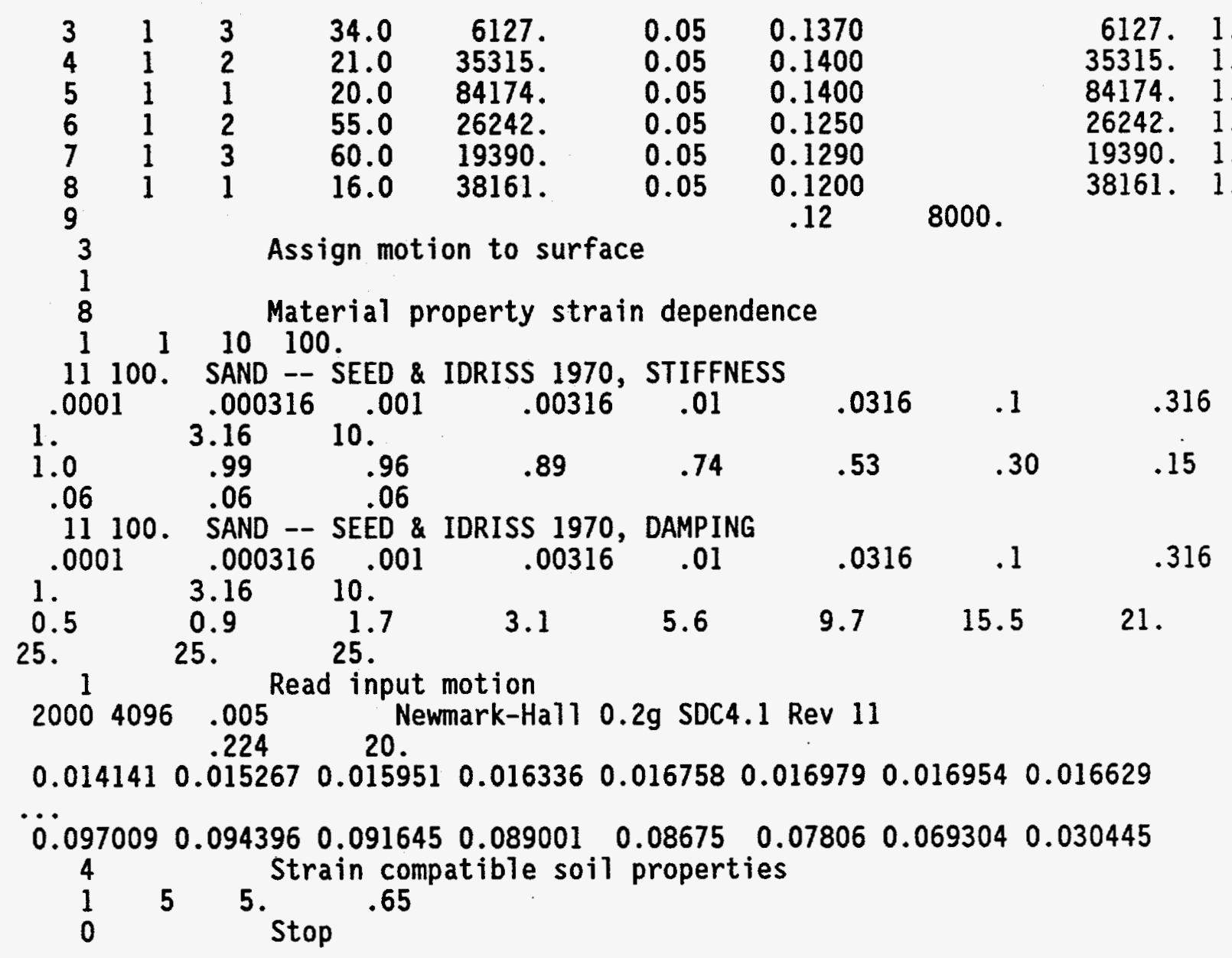

Several other comments can be made with respect to Options 2 and 8:

- The density input in Option 2 is in ksf.

- Use damping factor $B F A C=1$ if Option 8 describes the damping.

- The shear moduli and damping values (GMOD and B, CC 26-45) entered in Option 2 are initial guesses used to start the free field iteration process called for by Option 8.

- Note that the last Option 2 card is for the elastic halfspace and that one need only enter the layer number, density and starting shear velocity.

- The water level is specified by the sublayer number, not the layer number.

- Note that Option 8 does not have a material type entry (1=clay, 2=sand, etc). Instead, the first material presented is for clay called out for in Option 2, and the second material is for sand. If the user has onty sand in the model and shows only one material in Option 8, the run aborts. There is a fourth material type which appears to be a cube root sand correlation.

Program fs determines Fs factors for SHAKE option 2 from soil density and shear velocity profiles. Coefficient of earth pressure is .45 (SHAKE 
default). Option 8 must be used to enter the iterated to low-strain shear modulus ratio. Initial guesses output are .05 damping and input shear modulus. The latter could be used as a clay Fc by way of an editor. User must review output for validity to his problem.

Usage: fs <input >output

Input, one list directed line per layer with:

* dbot Depth of bottom of layer, ft

* vs Shear velocity, fps

* wt Density, pcf

Example input and output:

$\begin{array}{llll}10 & 850 & 135 & / \text { comment } \\ 28 & 1000 & 135 & \\ 62 & 1200 & 137 \\ 83 & 2850 & 140\end{array}$

$\begin{array}{rrrrrrrrr}1 & 2 & 1 & 10.0 & 3029 . & 0.05 & 0.1350 & 146.5 & 1 . \\ 2 & 2 & 1 & 18.0 & 4193 . & 0.05 & 0.1350 & 104.0 & 1 . \\ 3 & 2 & 1 & 34.0 & 6127 . & 0.05 & 0.1370 & 98.5 & 1 . \\ 4 & 2 & 1 & 21.0 & 35315 . & 0.05 & 0.1400 & 445.8 & 1 .\end{array}$

\section{HOUSEPLT}

This program is a simple translation of SASSI HOUSE module input to ANSYS version 4.4 PREP7 input suitable for mesh plotting. It is available on both the Cray and PC. User instructions:

- Read SASSI HOUSE input and translate for ANSYS 5.0 mesh plotting with boundary conditions included.

- EO Weiner 6/23/94

- Usage: houseplt <houseinput I asa >ansysinput \# Cray/ws houseplt <houseinput >ansysinput \# PC

- Protting can be done with the ansys system: ansys /show, 2d \# or whatever plot device /input, ansysinput eplot

- Since sassi element numbering starts with one in each group, offsets (appearing as ANSYS comments) are added to each group. The element offset is always a multiple of 100 .

- ANSYS type is HOUSE group in the order of appearance. This permits element group selection with ersel,type. ANSYS real is HOUSE geometry number for beams.

- Lumped masses are treated as Ansys unit mass elements under one group after the sassi element groups.

- Viewpoint along the negative $y$ axis is selected with $z$ up. This is suitable for 2D elements. For 3D elements, try /view, $1, .7, .5 ., 5$ at plot time.

- Boundary condition restraints (id=1) are not removed later in the ANSYS input when $i d=0$ is prescribed. The practice of first restraining all dofs followed by removing restraints at nodes in elements will show all dofs restrained. A work-around trick 
may be to remove the initial global restraint for houseplt processing and then putting it back in for SASSI processing.

- There is no checking for HOUSE consistency in this program. Check data first with the HOUSE data check option.

- ANSYS beam k-node doesn't generate like HOUSE. Translation uses the spar element.

- Translations of real values (areas, etc) and material property values (Young's modulus, etc) are not attempted.

- Node, element, type, material and real selections may be made at plot time using ANSYS Select Logic.

- Fortran source notation follows user's manual.

- ANSYS input is generated almost immediately as SASSI input is read in. Houseplt does not remember all nodes, elements, boundary conditions, etc.

- et, l,63 appears up front to active all 6 dofs and avoid warnings by $d-1$ ines before e-lines in ANSYS 5.0

- Element type mapping:

$\begin{array}{lrrrrrrrrr}\text { SASSI: } & 1 & 2 & 3 & 4 & 5 & 6 & 7 & 8 & 9 \\ \text { ANSYS: } & 45 & 8 & 63 & 42 & 45 & 42 & 8 & 42 & 27\end{array}$

Test input for HOUSEPLT is accessible to the user on the PC and Cray program files. The results are shown in Figures A.l through A.4.

\section{TRFILTER}

This short program is used to filter ANALYS transfer function output to selected nodes. User instructions:

Filter out transfer function print from ANALYS output.

Usage: trfilter <analys.out >output \# Cray

List nodes for desired output on fort.10, any order, 1000 max.

Filter on/off is depends on Fortran ANALYS output headings.

\section{HFILTER}

This short program truncates the extensive node and element output from HOUSE and leaves the message "etc, etc, etc".

Usage: hfilter <house. out >output

\section{SMFILTER}

This short program truncates the extensive time history output from MOTION and STRESS and leaves the message "etc, etc, etc".

Usage: smfilter <motion.out >output

\section{RDTABLE}

This short program reads $i / 0$ tables provided with the validation inputs, and generates script files for running the related SASSI modules. The generated script files are not to be considered complete. The user must check and usually modify them. User instructions: 
Read sassi validation problem $i / 0$ tables and generate scripts. Usage: rdtable <table >script

Move right half of table under left half and dup module column. Input format is $(4(1 x, a 7), 1 x, a 8)$ for module, ..., tapeout. Note right half input column is narrow ( 6 cols), make it 7 . Needs underscores in first column to separate out modules. Users checks results. Cannot handle PGMIMP of Table 12.

First non-blank 1 ine is output as comment.

Cols 11-40 in header after "MODULE" are output as comment.

\section{REFERENCES}

A1. HB Seed, et al., "Moduli and Damping Factors for Dynamic Analyses of Cohesionless Soils", Report No. UCB/EERC-84/14, Earthquake Engineering Research Center, University of California, Berkeley CA, September 1984. 
Figure A.l Houseplt/ANSYS boundary conditions

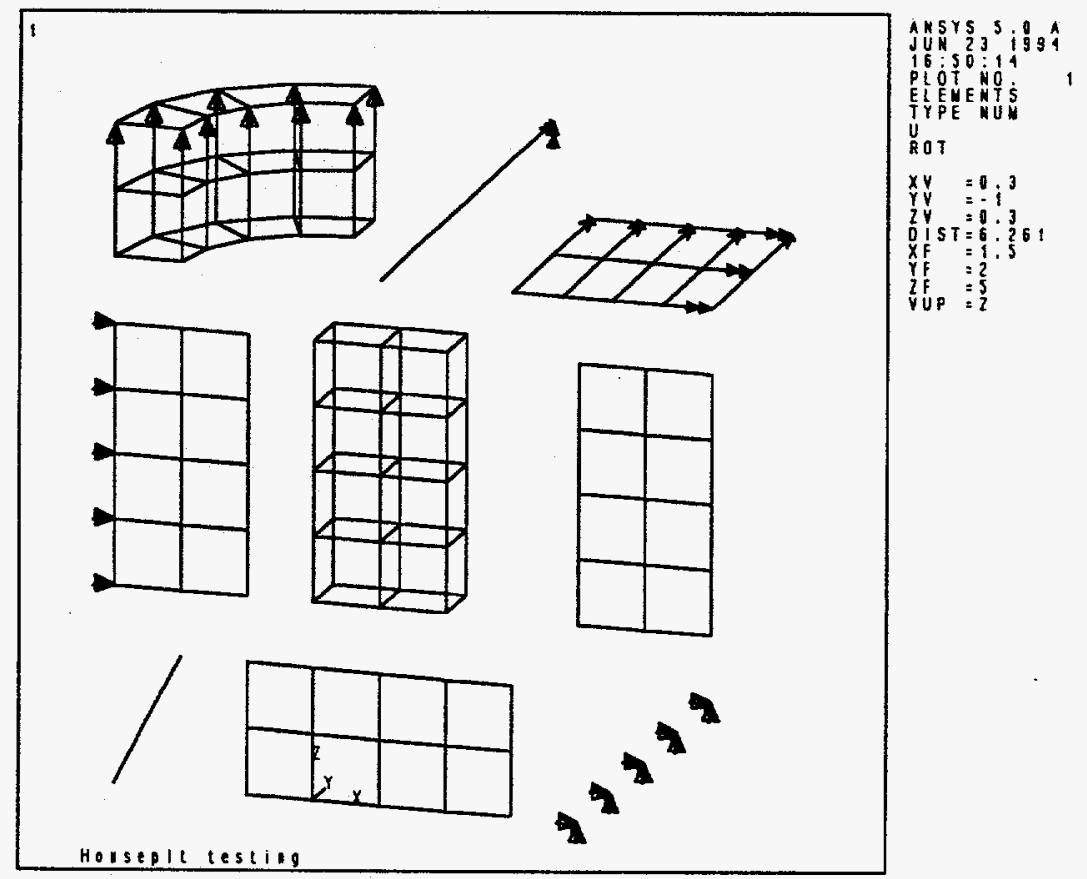

Figure A.2 Housep 1t/ANSYS element outlines

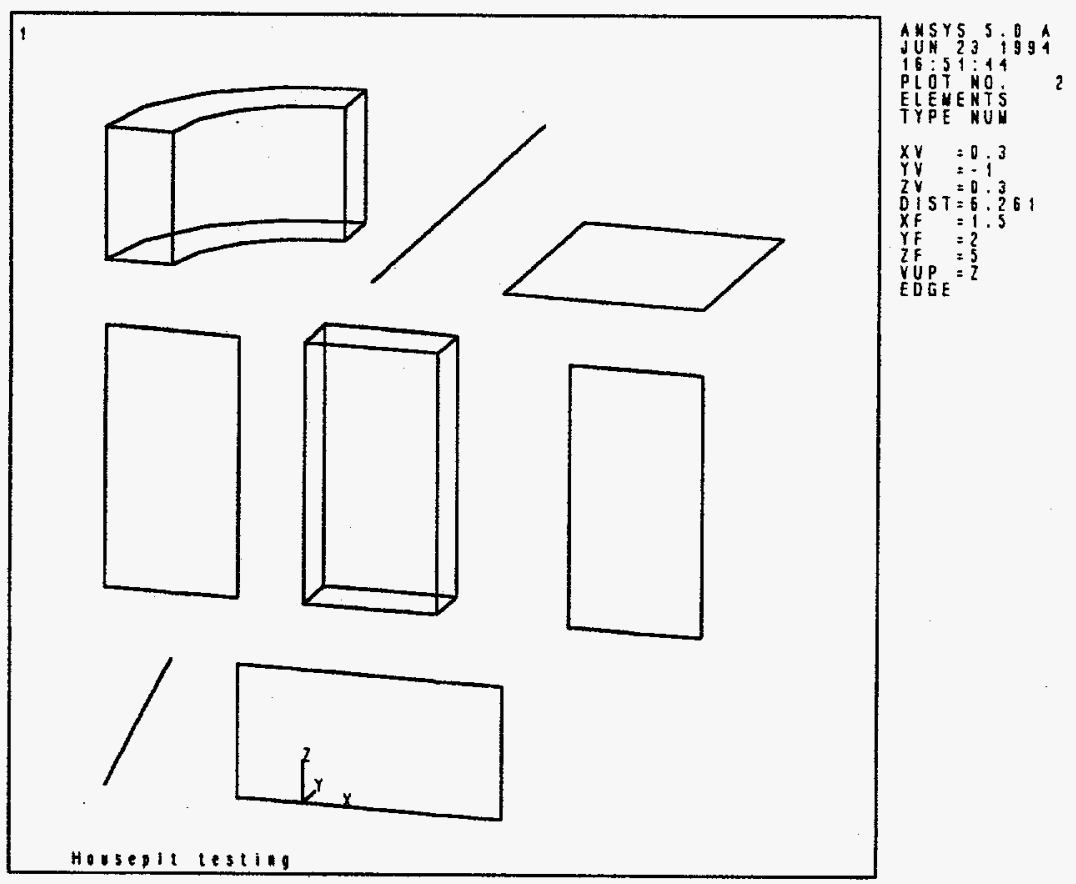


Figure A.3 Housepit/ANSYS element numbers
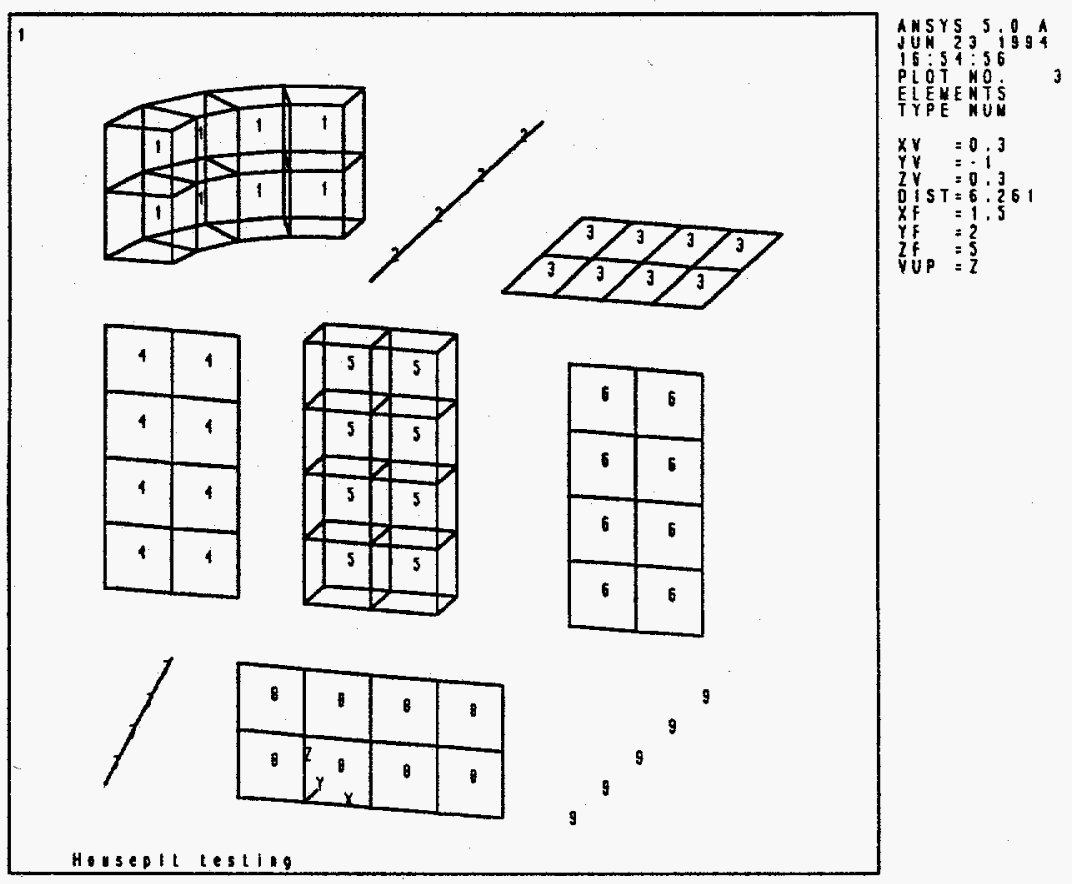

Figure A.4 Houseplt/ANSYS material numbers
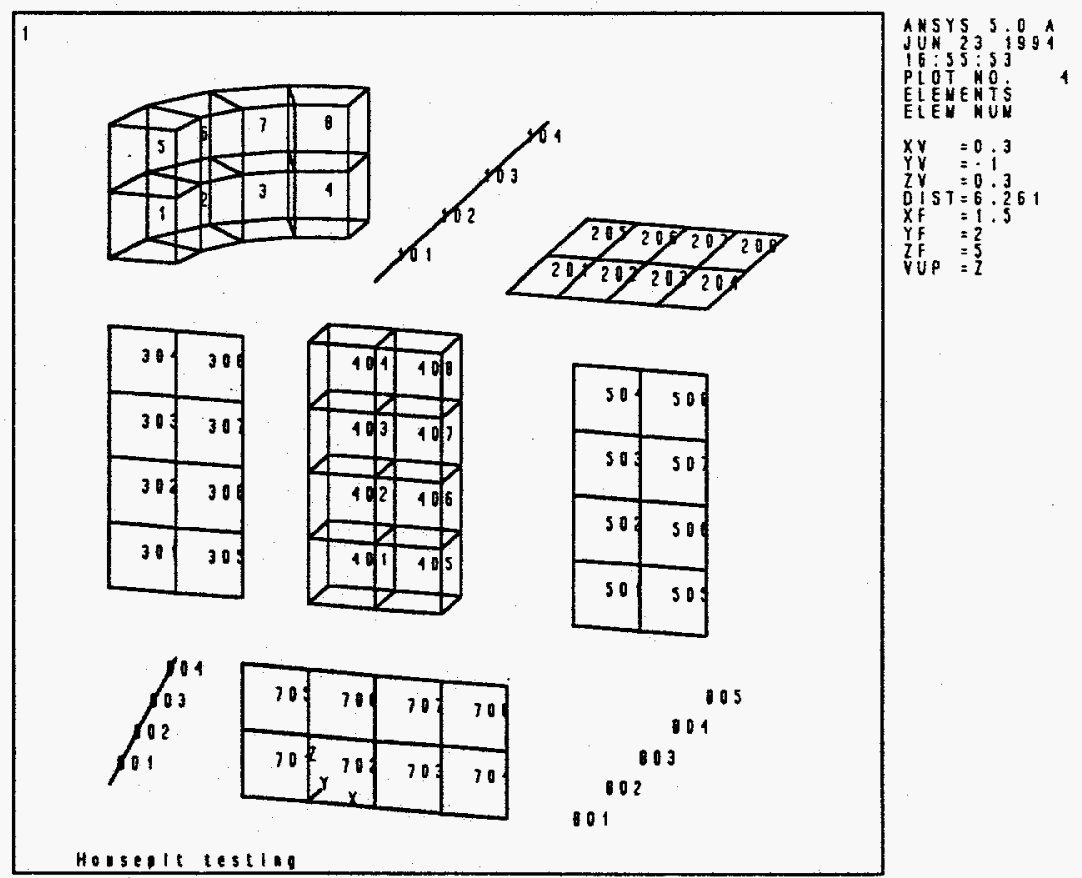
WHC-SD-GN-CSWD-30036 Rev 1

Page B-1

Appendix B. Conversion 
Appendix B. Conversion

\section{SASSI INSTALLATION}

Example input e2pd was renamed e2clpd for consistency. Source files csite.f, chouse.f, etc were renamed site.f, house.f, etc, and executables take the same names without extension.

All original source lines with $c c 73-80$ serial numbering were retained, commented out if necessary. Added lines are in lower case without serialization.

Module analys.f uses units 5 and 6 for unformatted $i / 0$. This conflicts with stdin and stdout, so the ANALYS streams were redirected to fort.95 and fort.96 with open statements. Users must recognized this when manipulating files between modules.

Modules house.f and analys.f, as received, utilized dynamic memory expansion in subroutine files2. The COS memory ('uc', nnn) call was replaced with the Unicos fortran callable sbreak(nnn). This is the alternate method suggested in Appendix D of the CFT77 manual. Note that the CFT77 Appendix D primary recommendation of using heap allocation was found to be useless - it passed the small program test but failed in the final application. The original variable NAVA in routine files 2 is a fixed maximum memory size. This was replaced by an upper bound memory resource limit which is machine and environment dependent. Communication of this limit is done by the routine iclim.c which calls the Unicos limit(2) system routine. The use of sbreak requires a fixed heap size of $1.2 \mathrm{Mw}$ is identified in the segldr options along with identification of blank common as dynamic. The large heap size was chosen as Cray and INEL operational personal indicated that $32 \mathrm{Kw}$ might be needed for each open $i / 0$ unit, and analys shows 30 units in the program statement. For the argument in the sbreak call, the maximum resource figure is reduced by the size of the executable (size house, includes the heap) plus a substantial -1-2 Mw cushion to eliminate uncertainties found in different environments. An sbreak error return causes the program to stop. Contrary to the original scheme, sbreak is called only once at the start of the run rather than allow blank common to expand and contract as calls to files2 are made during the execution. A small program nsbtest was written to test this memory expansion scheme in both batch and interactive environments.

A user was trapped by HOUSE/ANALYS memory restrictions in a restart attempt as discussed in the user appendix. Rather than force him to rework the entire problem, the 100K cushion (see above) in files2 of ANALYS was temporarily removed, and he was able to continue after recompilation. The practice is not encouraged. A larger cushion in HOUSE ( $+1 \mathrm{Mw}$ over ANALYS) is employed to help avert such problems.

Stress runs aborted when beam time history output was requested. The compiler warning that varible LL is used but undefined in beam output led to a small 
correction to get full fft output.

OPTIMIZATION

Since SASSI is known to consume computational resources for 1 arge embedded basement configurations, a few optimization checks were performed on the RL system. The default compilation options appear to optimize the program as well as can be expected.

\section{SHAKE INSTALLATION}

The input/output file query feature was replaced by redirection by commenting out the open statements for units 5 and 6 . Option titles written to the console were commented out, as the runs are relatively short ("minute). The seven figure accuracy for shear modulus output during iteration was reduced to six, so that output has a better chance of being repeatable across PCs. Also, time history table columns were move closer together to facilitate printing output. Finally, one instance of an embedded blank in the test input was replaced with a zero. The effect of the embedded blank can be seen in the third property curve in the printed output found in the manual. The proper output, as provided by the digitized test output, has a smoother curve.

Installation on the Cray required modification, because character variables were mixed with non-character variables in common blocks. The idnt and title character variables were moved from /EQ/ and /SOILA/ common blocks to their own blocks /EQC/ and /SOILAC/.

The FACTOR output field of Option 2 was widened to accommodate larger values that may be desired if one uses the FLUSH practice of entering low strain moduli as Fc. The time history sequence check was disabled - we no longer punch cards.

\section{SHAKE91 INSTALLATION}

SHAKE91 was received as source, executables, and test input and output. The executable failed, with or without the extender provided. The source was installed on PC with f771, on LANL Cray with cft77 and on SECC sgi3 with f77. Timing is $1: 2: 48$ for Cray:sgi3:486/25.

The following problems were encountered on sgi3:

- sgi3 cannot output certain Hollerith constants in format statements. It seems associated with lack of commas between constants. Commas were inserted in SHAKE9l and SHAKE.

- Common block alignment problems associated with character and real variables in one block were corrected as in SHAKE. No al ignment problems were noted from complex and real variables. Integers are $i * 4$. Retyping reals to $r * 8$ would cause alignment problems.

- Acceleration $t / h$ file name read in with Option 3 must not have leading blanks. Introduced code to remove blanks.

- Test input option 7 had an extra blank line; removed.

- Test last line did not read; replaced.

- + ITERATION output caused overprint; added blank 1 ines.

- Frequency step in Option 10 different in test input vs output. 
Considered a supplier mistake.

Additional changes:

- Added code to take Poisson's ratio input in Option 2 in cols 66-75 for each layer and produce iterated soil property output suitable for SASSI input. User must insure consistency of units.

- Stress/strain output is 1imited to 2049 steps. This was increased to 4096 with additional testing.

- Usage modified like SHAKE:

Usage: shake91 <input >output \#t/h output on file "punch"

- Rearranged SHAKE91 routines like SHAKE and differenced the sources. Only one obvious difference: shake9l/time/ has $t(9)$ which clearly should have been $t(2049)$. Changed to $t(4096)$ which corrected frequency output in the amplification option.

\section{BLANK LINE HEADER IN PC MODULE OUTPUT}

Modules SHAKE, HOUSEPLT, TRFILTER and RDTABLE are available on PC/DOS systems as well as the Cray. Their stdout output (to files by redirection) always adds a blank line at the top on a PC, but not on the Cray. This is immaterial as blank lines in HOUSEPLT output are ignored by ANSYS.

\section{CUSTODIAL NOTES}

Moving compressed and tarred files such as sassiusr.tar and sassi.tar.Z with FTP should always be done in the binary mode. 
Appendix C. Testing Details 
Appendix C. Testing Details

Prior to RL installation, testing was carried out by Bechtel for Savannah River for 18 examples as discussed in the main body of the report. The validation report and example inputs were provided to WHC at the time of the $\mathrm{RL}$ Cray installation in 1991 . Validation report examples $2,5,9,11$, and 17 as received from SRP were tested on the RL Cray and compared with the report results and found acceptable. Example 2 and Example 9 Case 5 were adopted for in-use testing since they exercised all the modules. In-use testing includes differencing with reference output. Example 2 later showed $10-20 \%$ changes at a change of operating systems from Unicos 5.1 to 6.1 . The problem was traced down to ill-conditioning: beams linking a rigid containment pad to stick models representing containment and internals were much stiffer than necessary. The problem was not with the code. It was with the model which was corrected, and the in-use test was revised accordingly.

Installation on the INEL Cray in early 1994 passed the in-use test. However, a waste tank model, identified here in as 98 , produced anomalous behavior under certain circumstances. Various tests with the model showed that anomalous results were obtained if the number of structural blocks in the stiffness matrix is 1 in the house output. If more than one block resulted, which could result from a smaller memory allocation, good results were obtained. Bechtel and CEC personnel offered to run the problem on their IBM RISC and Cray installations, and all produced good results. This anomalous behavior was restricted to the $q 8$ model at INEL. An additional problem at INEL, found by fixing the memory and running the q8 1-block model, produced an Operation Range Error in the house module. A quick installation on the gamma machine at LANL proved good with one block in both the variable and fixed memory configurations.

For LANL installation, it was decided to run all 18 Bechtel test cases and compare with RL output obtained by KEH in an effort following the RL Cray installation (Luo 1994). Both in-use and q8 tests proved satisfactory. Testing with Bechtel validation cases proceded as follows.

- Differenced KEH and SRS inputs, ok

- Differenced KEH scripts against those generated with SRS tables input to rdtable, ok

- Ran KEH inputs at LANL with rdtable scripts

- Differenced KEH/RL and LANL outputs after trfilter, hfilter and smfilter on both outputs at sgi3. ok.

It should be noted that Example 12 needs 30 minutes and should not be aborted prematurely.

An MWTF 180 model of a buried waste tank tested ok. This model required three hours to run. The model caused anomalous behavior with the CEC ibm2 RISC demo 
version when combin was used to add 4 more frequencies to 12 frequency results. The model was sent to CEC.

An MWTF gtr model tested ok. This model required 2 hours of run time and had data available from the RL Cray as well as the INEL Cray. Two variants of the model existed: files rl/id at RL/INEL and files 1 anl/inel at LANL/INEL. Difference of $r l$ and id(INEL) outputs were ok. Difference of inel(INEL) and LANL were ok. This gives a chained ok to RL data.

Users are cautioned that the source of the anomalous results with the INEL installation was never identified, and consequently it cannot be argued that the SASSI coding was definitely not involved.

SHAKE and SHAKE91 were tested satisfactorily with the examples provided with the programs and described in the user's manuals. SHAKE9l punch files from LANL, SECC and the PC platforms were checked against the output provided by the vendor. In addition, the soil profile analyzed with FLUSH (Winkel, 1991) was reanalyzed with the Fc correlation in SHAKE as shown in the example of Appendix A. SHAKE9l was also used with the data. The comparison of the three results in Figure $\mathrm{C} .4$ is considered excellent.

Testing the PC modules by the custodian is somewhat cumbersome. The reference outputs are from the SECC Unix systems and show minor differences with the PC output. To view the differences in a reasonable manner, it is suggested that the reference outputs in the PC server $k$ : \eow $\backslash$ sassi directory have the first column removed after they are copied there with sassires.bat. This essentially converts Fortran carraige control to ASCII carriage control. Also, the houseplt.out file has $0.0000 E+00$ terms which should changed to 0.0000 bbbb ( $b=b 1$ ank) with a text editor. Then the PC outputs can be differenced with the reference outputs. The modifications and differencing are best done on a Unix system. When found satisfactory, the PC outputs should be moved to the reference outputs in the PC server $k$ : \eow $\backslash$ sassi directory to make it easy on the user to test with his own machine. 
Figure C.1 Example 2 Case 3 Transfer Function Magnitudes

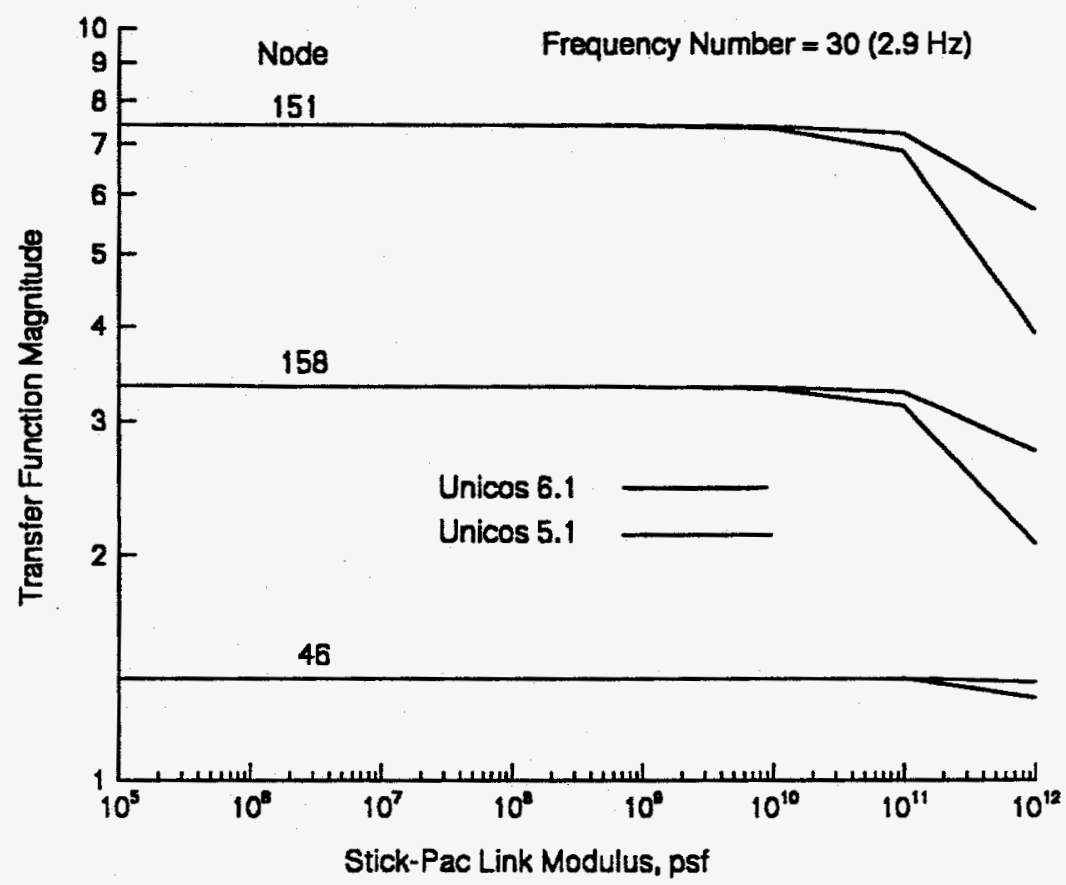

Figure C.2 Example 2 Case 2 Node 158x Spectra

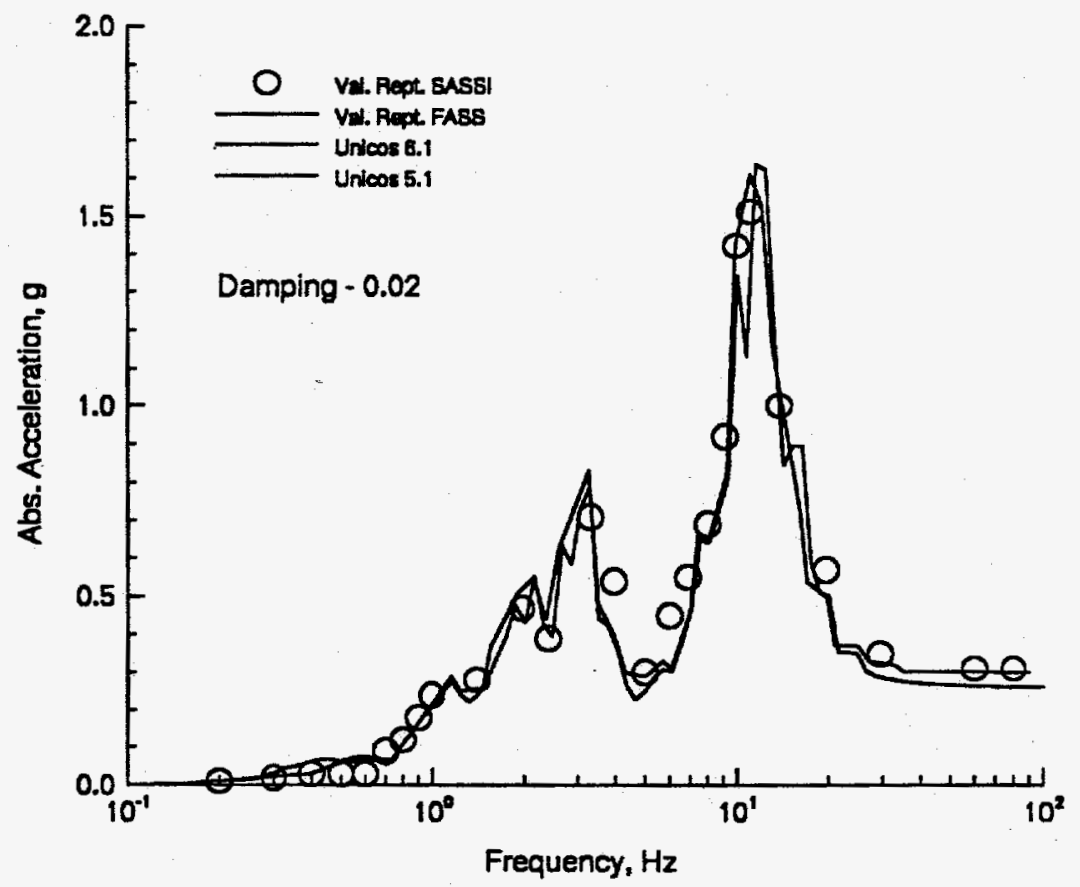


Figure C.3 20 Cycle Sine Response Spectra

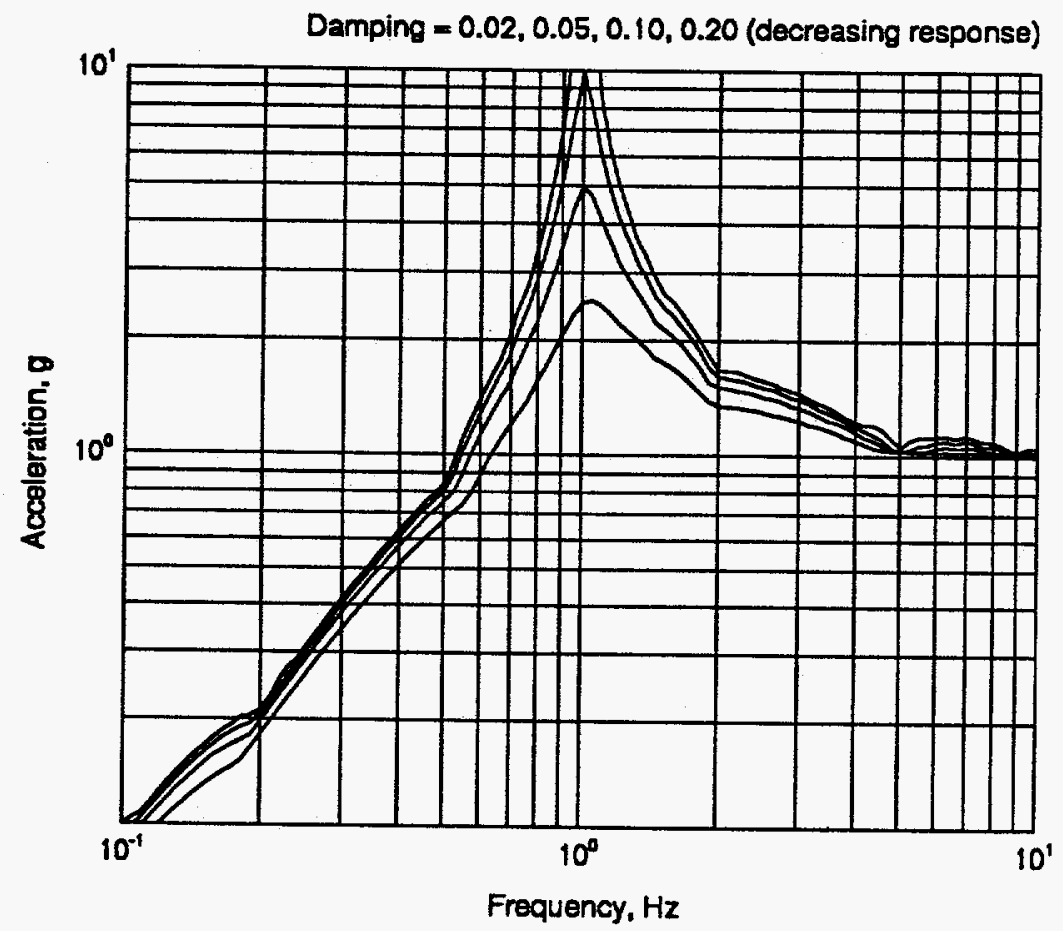

Figure C.4 SHAKE/FLUSH Comparison of Iterated Soil Properties
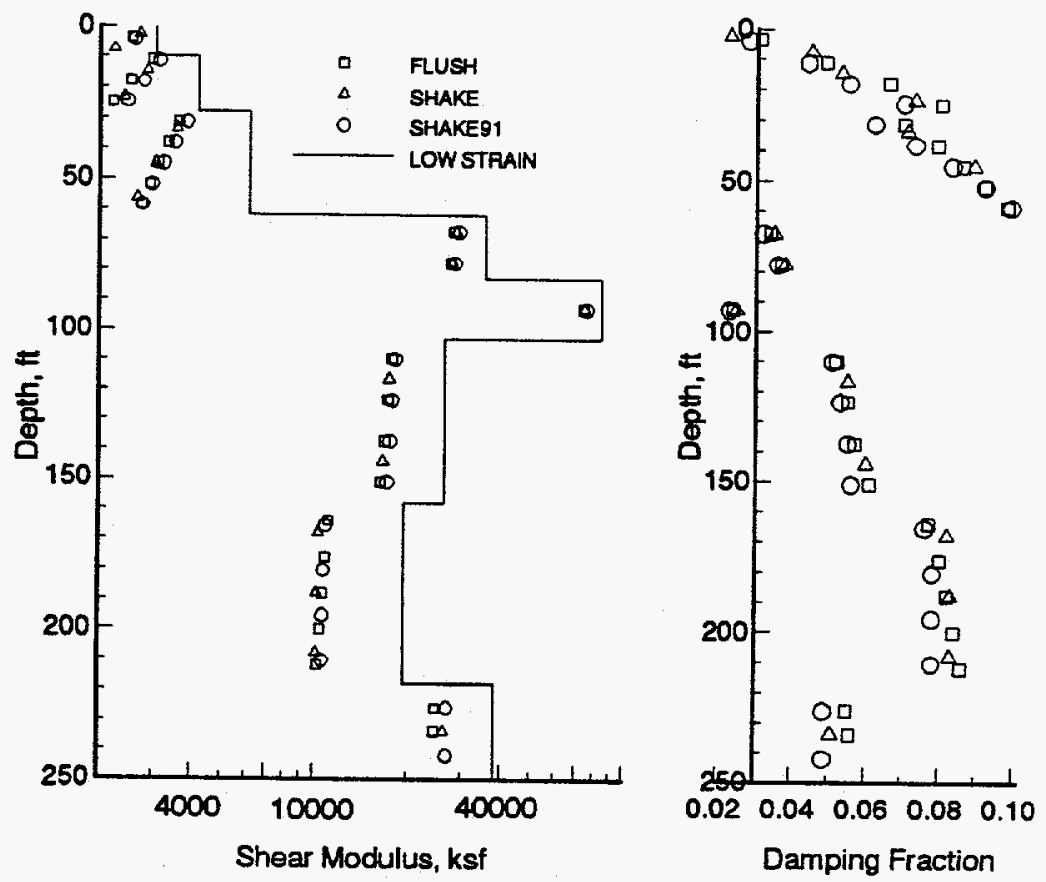